\title{
ECONOMIC EVALUATION FOR INPUTS AND OUTPUTS OF THE MOST IMPORTANT CEREAL CROPS IN EGYPT
}

\author{
FAIZA AHMED MOHAMED AHMED
}

\author{
Agric. Econ. Res. Instit- ARC, Dokki, Giza, Egypt
}

(Manuscript received 29September 2016)

\begin{abstract}
$\mathrm{T}$ he study aims to Search evolution of the Indicators to productivity and economic for Crops of wheat, maize, rice during the period (2000-2014) And analysis the effect of government intervention in production for the period (2012-2014)، The results indicate that average annual to cultivated area each them estimated at 2,9،1,8, 1,5 million Feddan, respectively, As it turns out it increases annually by about 72,35 . 32,05 thousand Feddan, represent about 2,50, 1,24 percent of the annual average area of wheat and maize, And that the area planted with rice characterized by relative stability, and this may be due to government intervention in determining the cultivated area. The annual average productivity per Feddan for study crops, Wheat, maize, rice, estimated at about 2,6, 3,38، 4 tons each, respectively, It was found that all a study crops was characterized relative stability, Annual average of total production of a study crops have been estimated about 7,7, 6,1.5,8 million tons, each for which respectively, the annual average for Farm price of study crops have been estimated around 1579، 1237،1356pounds per ton, respectively, It was found that is increasing annually about 156 . 89، 121 pounds per ton represents about 9,86، 7,23، 8,94 \% the annual average farm price. The total return amounted to about 4242، 4246، 5386 pounds per Feddan It increases annually by about 553,7 ،466,95 ، 539,2 pounds Represents about 13,05,11، 10,01 percent of the annual average from total income, the average total cost was around 290, 2881، 3305 pounds per Feddan, and is growing annually at about 282,4، 270,8 ، 292,7 pounds per Feddan represents about 9,71 ، $9,40,8,86 \%$ of average total costs the average net return per Feddan was around 1333، 1371,2081 pounds and is growing annually at about 271,3, 196,8، 243,3 pounds, represents about 20,35، 14,35, 11,69 percent of the annual average net return. Nominal Protection Coefficient estimate for wheat crop was about 1,07 , indicating that the state provides support to producers of wheat, while the Maize and rice crops, has been estimated 0, 64 ، 0,43 indicating that producers bear the implicit taxes by the state $\cdot$ Nominal Protection Coefficient estimate for Production requirements to the three crops valued at less than the one undivided, which indicates that the government provides clear support for imported inputs, which estimated at $0,26,0$, 24 ، $0,27 \%$ from the value of inputs. Effective Protection Coefficient for Wheat ، maiz, rice, crops estimated at $1,15,0,61,0,41$ respectively, which indicates that there is effective protection to producers of wheat, While maize and rice producers bear implicit taxes, Comparative advantage coefficient estimated at $0,67,0,56,0,24 \%$ which indicates a comparative advantage to Egypt in the three crops production.
\end{abstract}




\title{
التقييم الاقتصادي لمدخلات ومخرجات أهم محاصيل الحبوب في مصر
}

\author{
فايزة أحمد محمد أحمد \\ معهد بحوث الاقتصاد الزراعي- مركز البحوث الزراعية - دقى - جيزة \\ الملخص
}

تهدف الدراسة إلى دراسة تطور المؤشرات الإنتاجية والاقتصادية لمحاصيل القمح، الــذرة

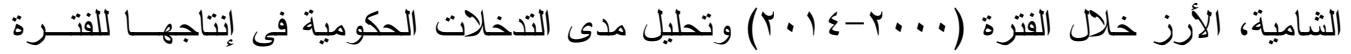

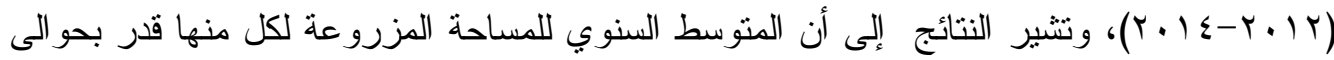

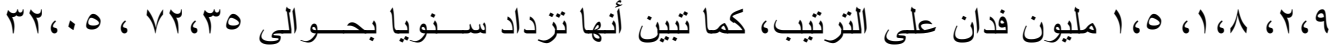

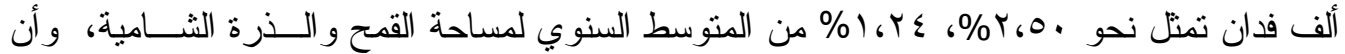

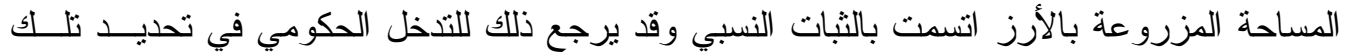

قدر المتوسط السنوي للإنتاجية الفدانية لمحاصيل الدراسة القـــح، الــذرة الثــامية، الأرز

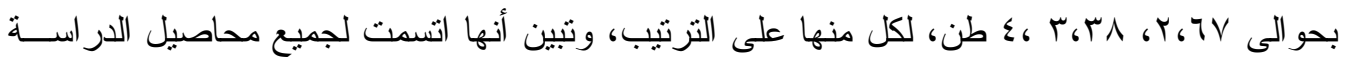

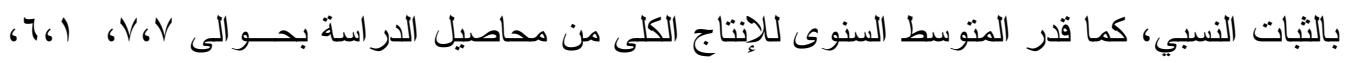

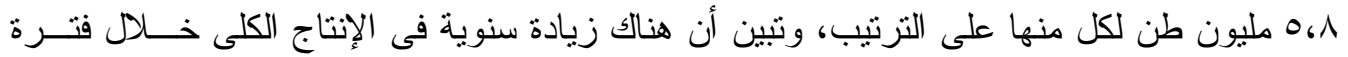

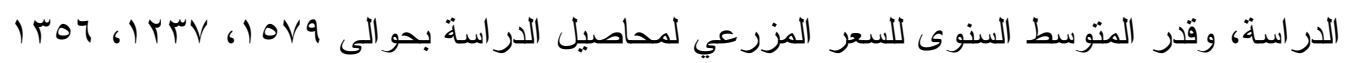

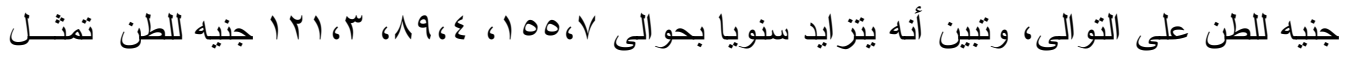

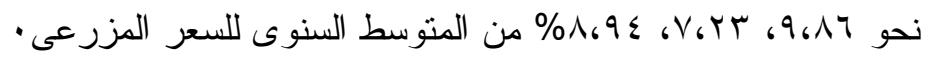

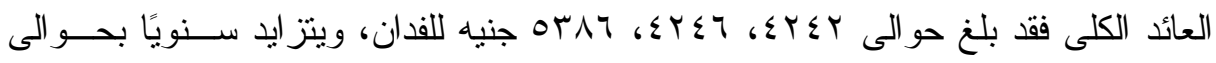
15

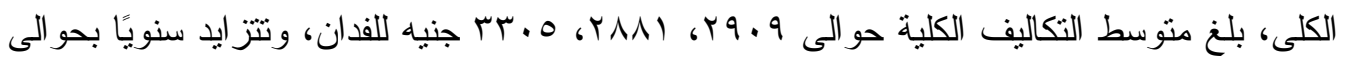
ع ؛

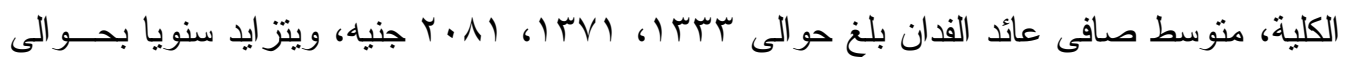

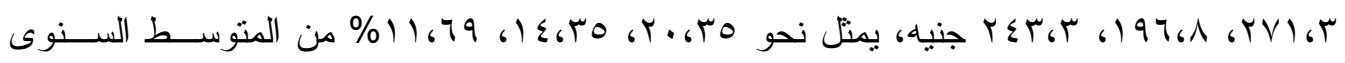
· لصافى العائد

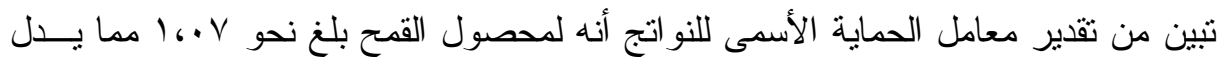

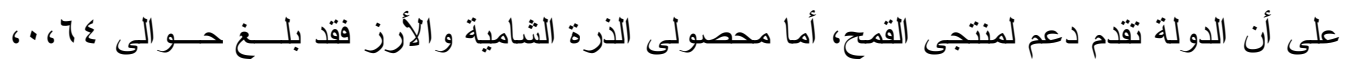

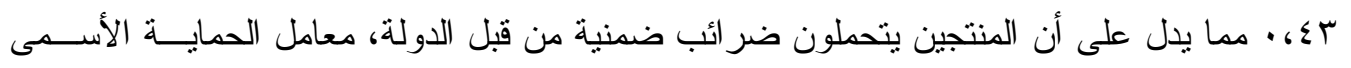

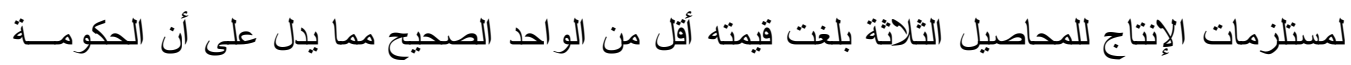

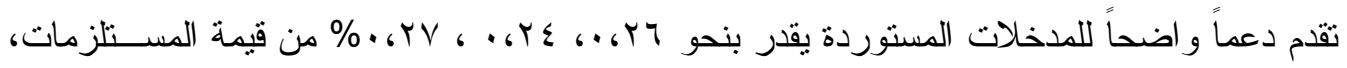

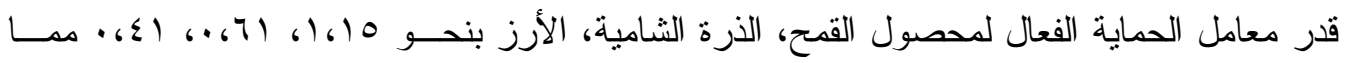




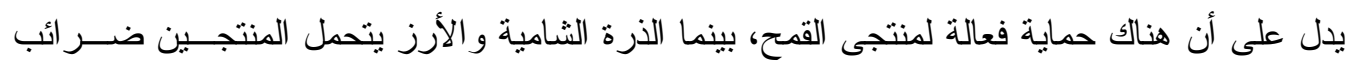

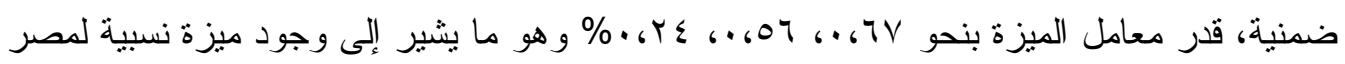
فى زر اعة المحاصيل الثلاثة.

\section{المقدمة:}

تعنبر محاصيل الحبوب من المحاصيل الإستراتيجية الهامة في القطاع الزر اعي المصري الذي يعد ركيزة أساسية من ركائز الاقتصاد المصري، وتعد تلك المحاصيل المسئولة عن الأمن

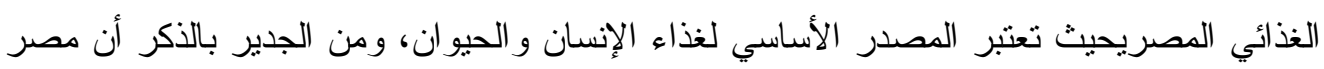

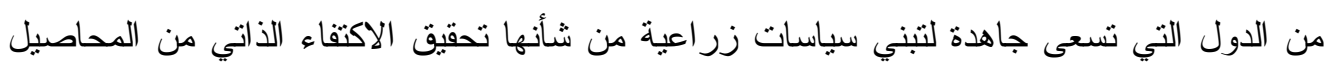
الزر اعية بصفة عامة ومحاصيل الحبوب بصفة خاصة. تشير بيانات الإدارة المركزية للاقتصاد

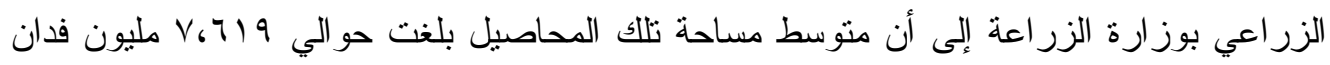

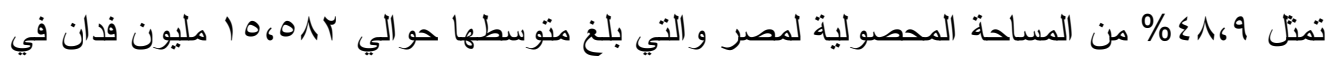

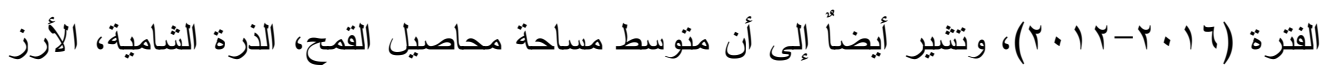

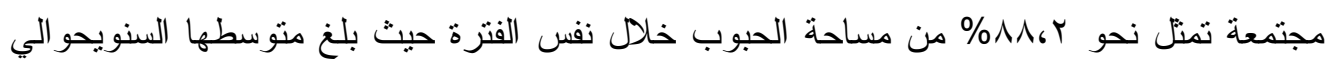
111

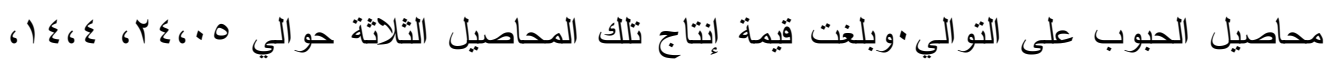

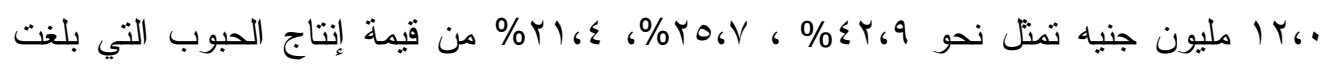

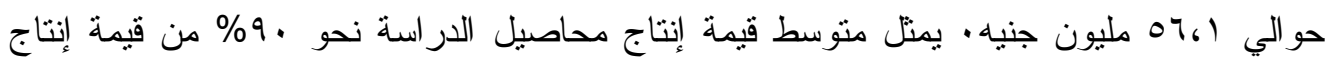

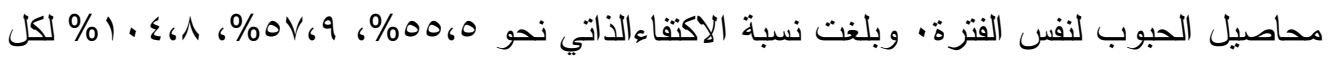
من القمح، الذرة الثامية، الأرز · وبلغت نسبة الاكتفاءالذاتي من إجماليمحاصيل الحبوب نحوبة نهو

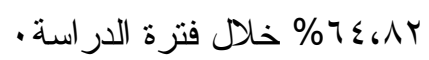

المشكلة (لبحثية:

تكمن المشكلة البحثية في عدم وفاء الإنتاج المحلى بمتطلبــات الاســــلالك المحلـى مــن

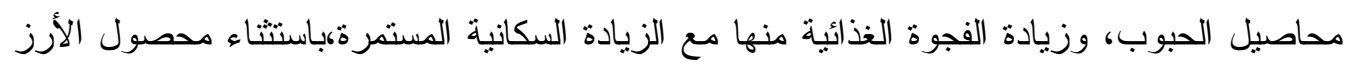

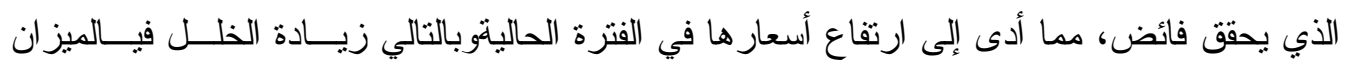

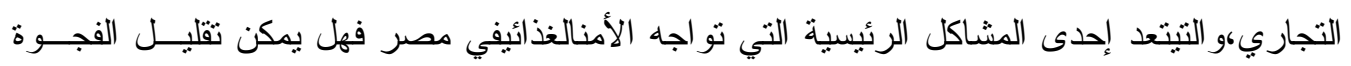
الغذائية منها، وما هيآليات تقليل هذه الفجوة ؟ الفئي

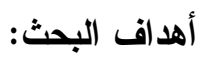

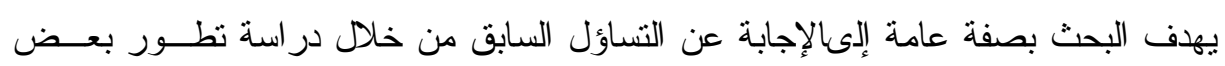

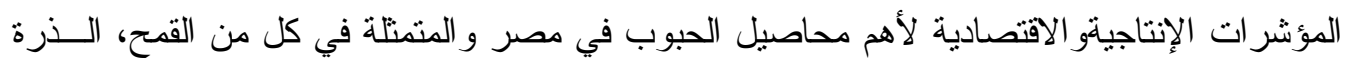

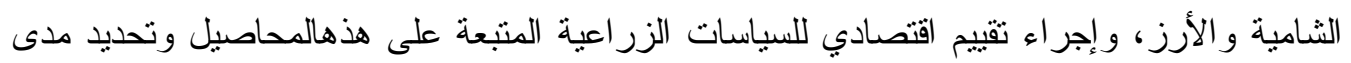

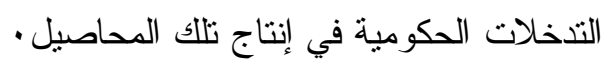
الطريقة البحثية ومصادر الحصول على البيانات: 
اعتمدت الدراسة على أساليب التحليل الإحصائي الوصفي لتوصيف الدراسة و التحليل

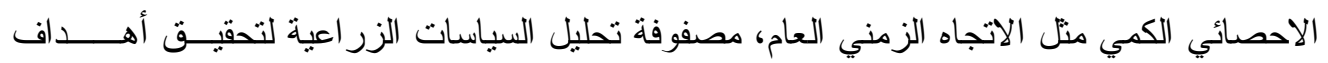

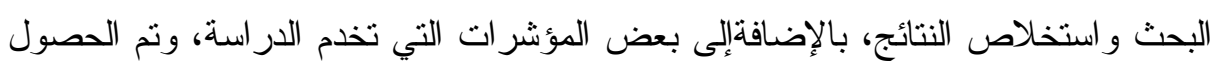

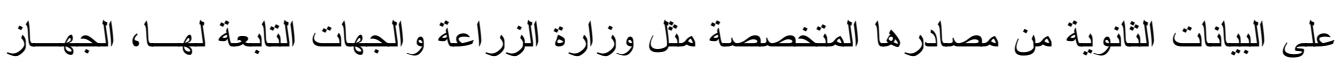
المركزي للتعبئة العامة و الإحصاء، وشبكة المعلومات الدولية.

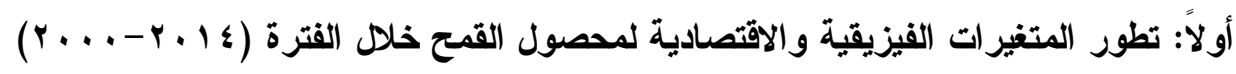
1- ت تطور المساحة المزروعة:

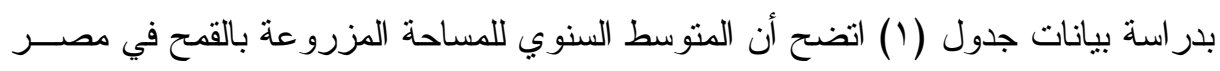

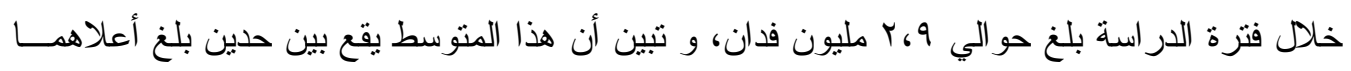

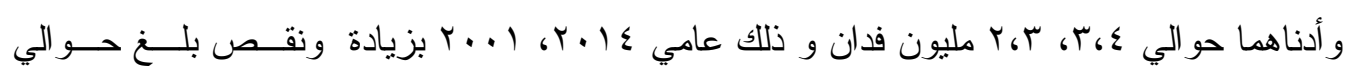

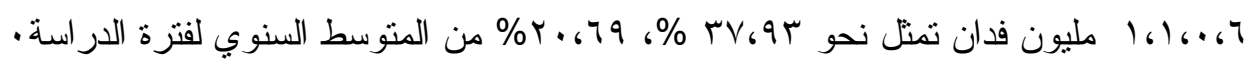

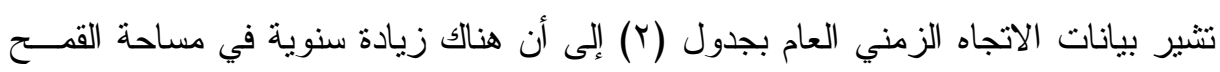

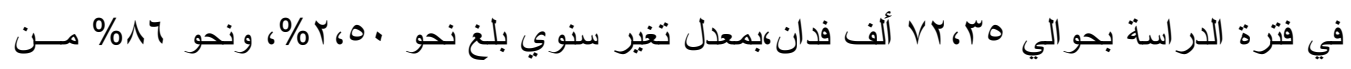

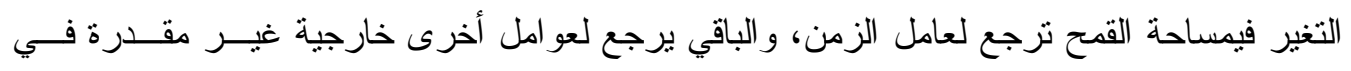

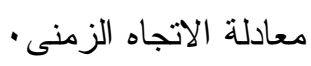

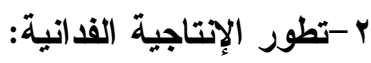

تبين بيانات جدول (1) أن المتوسط السنويلإنتاجية الفدانية للقمح المصري خـــله الفتــرة

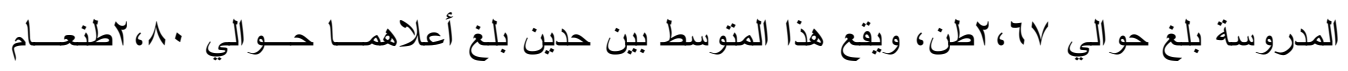

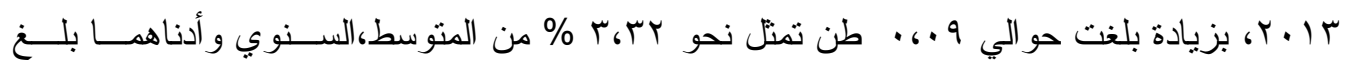

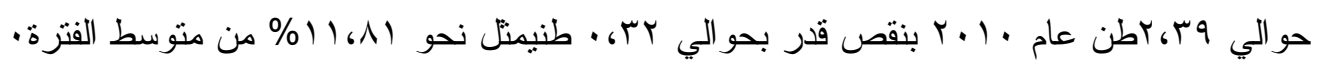

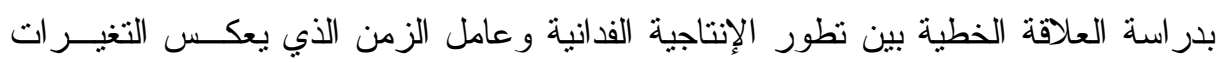

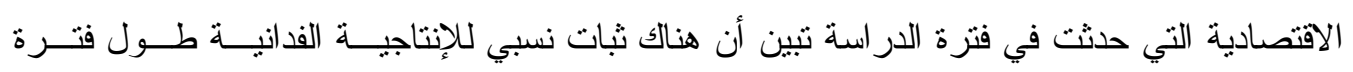
ب- الدر استكما بجدول (r). توضح بيانات جدول ( ) أن متوسط الإنتاج الكليمن القمح المصري خلال فترة الدراسة بلغ

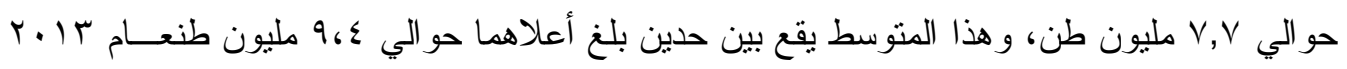

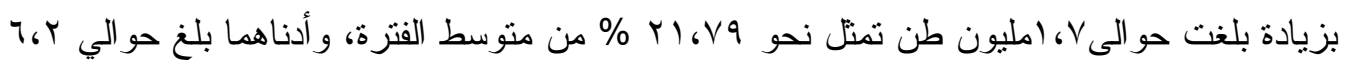

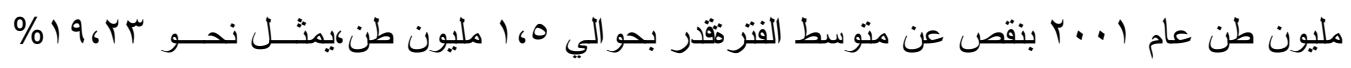

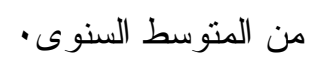
تشير معادلةالاتجاه الزمني العام بجدول (r) إلى أن هناك زيادة في الإنتاج الكلي لمحصول

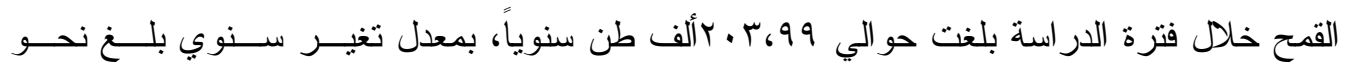

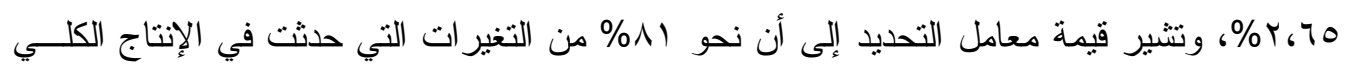

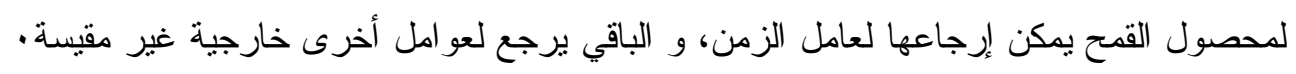


؛ - تطور السعر المز رعىللناتج الرئيسي:

توضح بيانات جدول (1) أن المتوسط السنوي للسعر المز رعي للقمح في مصر خلال فترة

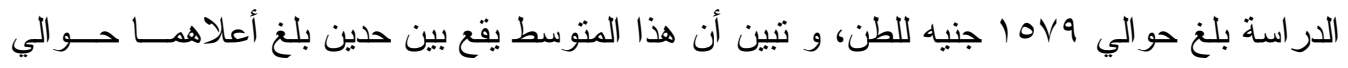

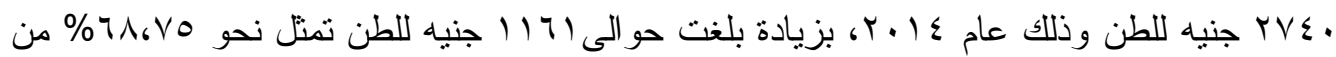

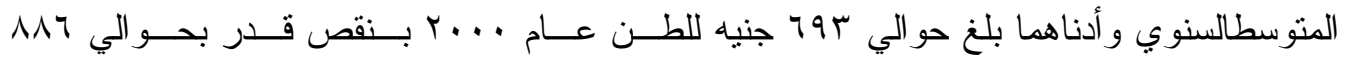

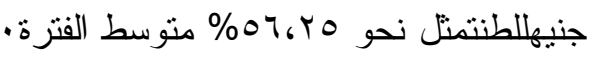
جدول (1) :تظور أهم العوامل المؤثرة علي إنتاج محصولالقمح في مصر

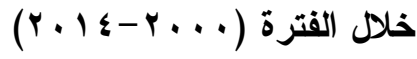

\begin{tabular}{|c|c|c|c|c|c|c|c|c|}
\hline بالجنيه & جنية/افئاند & جنيه/فذان الإيل اد & التكاليف & رعيجنيه / السعز & بالألف & للإلفداجية & بالألففدان & السنوات \\
\hline - , Ar & $r \leq$. & $1 \wedge 0$. & 101. & 794 & $70 V 7$ & r.TV & $r \leq 7 r$ & $r \ldots$ \\
\hline., 00 & Drro & $r v \otimes \wedge$ & 10rr & r & TrOH & r.7V & $r r \leqslant r$ & $r \ldots l$ \\
\hline$\cdot, \wedge I$ & & 19Y0 & 1009 & vir & 7710 & $r_{6} v$. & $r \leq 0$. & $r \ldots r$ \\
\hline • & rq. & $r \cdot V 0$ & ivio & V 7. & $\checkmark \wedge \leq 1$ & r.VT & Yo. & $r \ldots r$ \\
\hline$\cdot, 79$ & 107 & YVY. & 19.8 & $1 \ldots$ & $\vee 19$. & r.VY & Y Y.० & Y.. $\varepsilon$ \\
\hline., 70 & $1 . V V$ & $r . \Delta \wedge$ & 1911 & $11 \%$. & $\Lambda 1 \leqslant q$ & r.Vr & rqA० & r... \\
\hline - gr & 19. & rrr & $r \mid \leqslant r$ & $11 \mathrm{rV}$ & $T r \leqslant r$ & r.V. & צ & $r \ldots r$ \\
\hline$\cdot, \vee \wedge$ & $V \cdot \leq$ & r & $Y \leq \varepsilon \leq$ & 1104 & $V \leq 10$ & r.VT & rVIT & $r \ldots v$ \\
\hline - , $\{4$ & $r V \leq \Lambda$ & $\checkmark \wedge ৭$ & $r_{1} \leq 0$ & roor & $\vee \wedge \wedge \varepsilon$ & r.V. & rqr. & $r \ldots \Lambda$ \\
\hline$\cdot, \vee \vee$ & $1 . \leqslant 1$ & $\leq 0 \ldots$ & $r \leq 0 q$ & IVIr & $\wedge \vee \wedge$. & r.Vq & $r I \leqslant V$ & $r \ldots q$ \\
\hline$\cdot, \wedge 9$ & $\leq 7 r$ & $\leq 1 \leq r$ & rчs. & IVrr & VOYI & r.rq & $r I \leqslant V$ & $r+1$. \\
\hline זד, • & rrAo & $7 \leq 0 \leq$ & $\varepsilon .79$ & $r r \leqslant V$ & $\wedge r \wedge \theta$ & r.Vo & $r . \leq q$ & $r .11$ \\
\hline זד, • & $r \otimes \wedge l$ & $V \ldots q$ & $\leqslant \leqslant$ Y & ror. & $\wedge \vee \wedge \wedge$ & r.VA & r171 & $r .1 r$ \\
\hline •, TV & $r \leq 17$ & VYYE & $\leqslant \wedge \cdot \wedge$ & r०A. & $9 \leq \Delta \wedge$ & r.A. & rrv^ & $r .1 r$ \\
\hline$\cdot, v$. & rrrv & $\vee 0 . \wedge$ & orvi & $r V \leq$. & q ४qV & r.VE & rqu & $r .1 \leq$ \\
\hline$\cdot, v$. & rrri & $\varepsilon r \leq r$ & $r 9.9$ & $10 \vee 9$ & VV.. & r,TV & $r \wedge \wedge \wedge$ & المتوسط \\
\hline
\end{tabular}

المصدر: وزارة الزراعة واستصلاح الأراضي، قطاع الثؤون الاقتصادية، نشرة الاقتصاد الزراعي أعداد

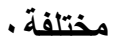

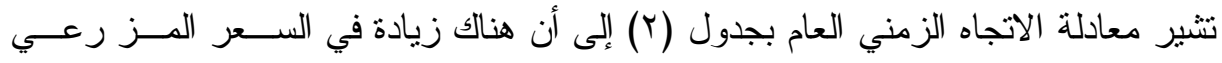

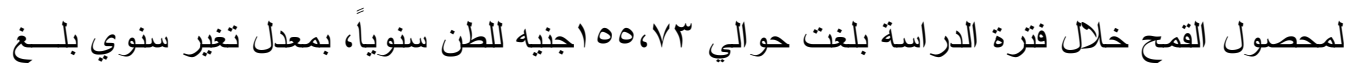




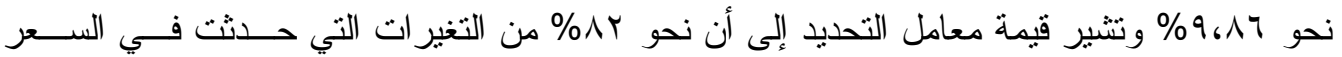

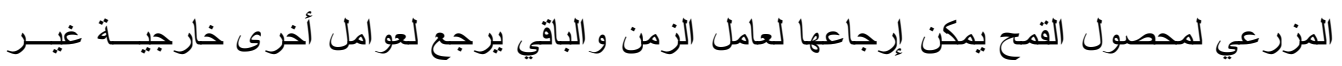

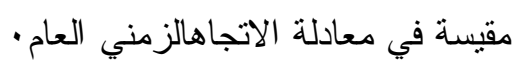
ه - تطور التكاليف الكلية: معاده

يبين جدول (1) أن المتوسطالسنوي للتكاليف الكلية لفدان القهح في جهم،ع خــلد الفتــرة

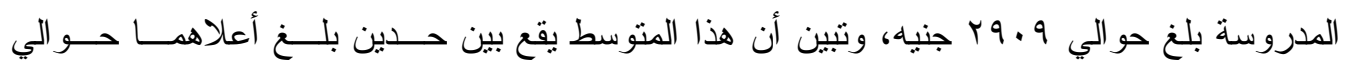

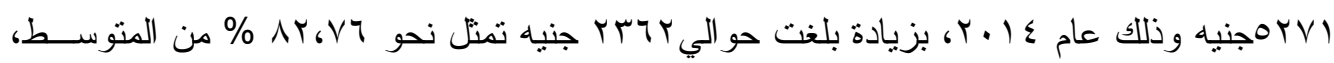

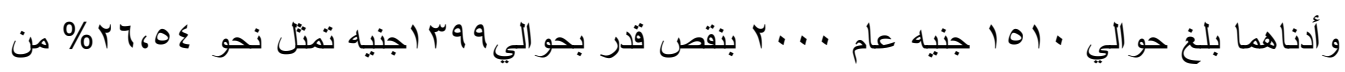
متوسط الفترة

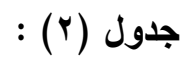

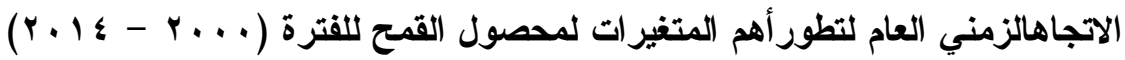

\begin{tabular}{|c|c|c|c|c|}
\hline معدل التغير \% & قيمة (ف) & נر & المعادلة & المتغير \\
\hline r.o. & Th,rt & די، & 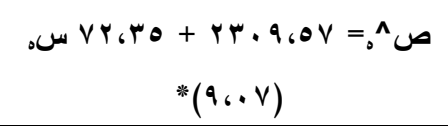 & المساحة المزروعة \\
\hline- & .rr & $\ldots r$ & 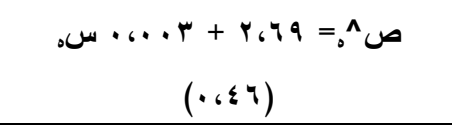 & الإتتاجية الفدانية \\
\hline r.to & $00, Y$ & . ‘A & 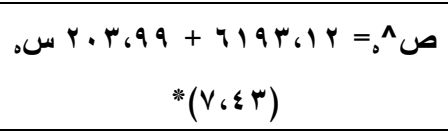 & جنيه للفدان الإنتاج الكلى \\
\hline $9 ، 19$ & 71,10 & • ‘Ar & 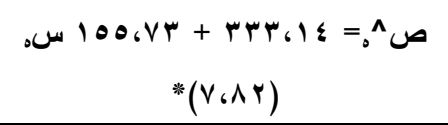 & السعر المزرعى \\
\hline 9.81 & 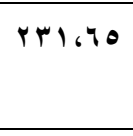 & .690 & 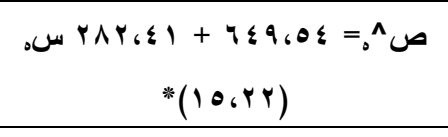 & التكاليف الكلية \\
\hline $14 . .0$ & ITr.Ar & . & 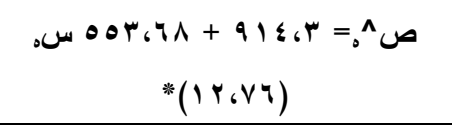 & جنيه للفدان الإيراد الكلى \\
\hline r.r.to & $7 \leqslant, \Lambda$ & . ، A & 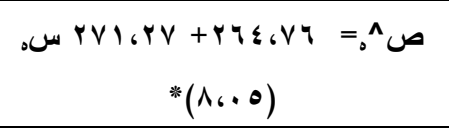 & صنيه للفى العاند \\
\hline- & r.r. & $.6 r$ & 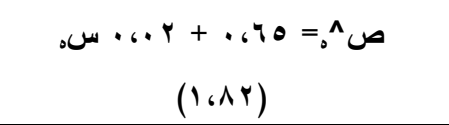 & عائد الجنيه \\
\hline
\end{tabular}

المصدر : حسبت من بياتات جدول (1) بالبحث .

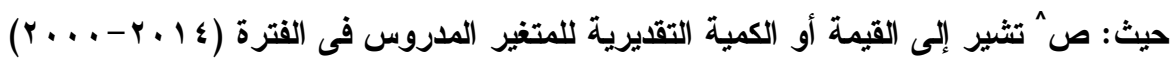

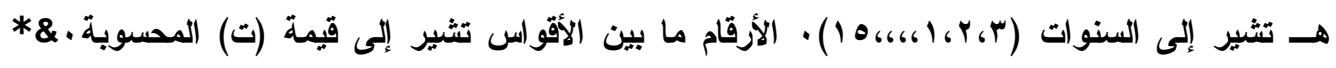

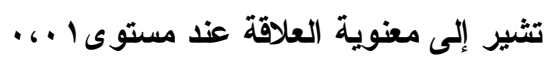

تشير معادلة الاتجاه الزمني العام بجدول (Y) إلى أن هناك زيادة في التكاليف الكلية لفــــان

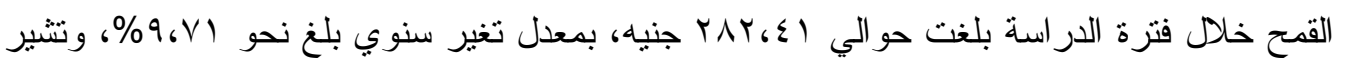


قيمة معامل التحديد إلى أن نحو 90\% من التغير ات التي حدثت في التكاليف الكلية لفدان القمح يمكن

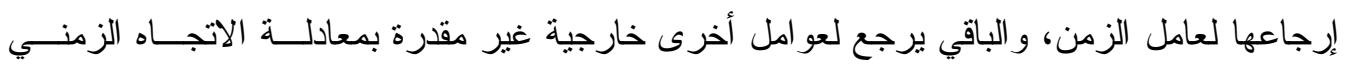

باستقر اء بيانات جدول (1) أتضح أن المتوسطالسنوي للإير اد الكلي لفدان القـح في مصـر

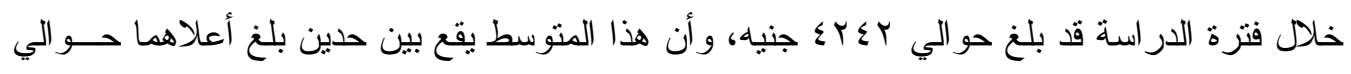

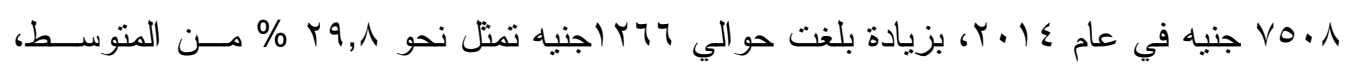

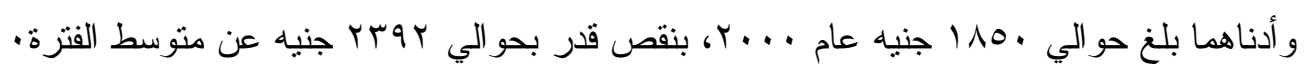

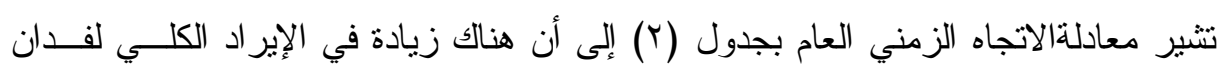

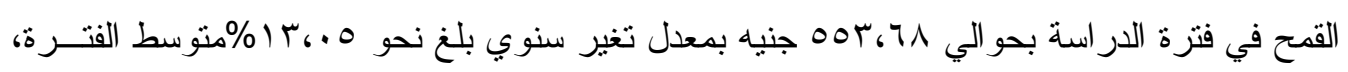

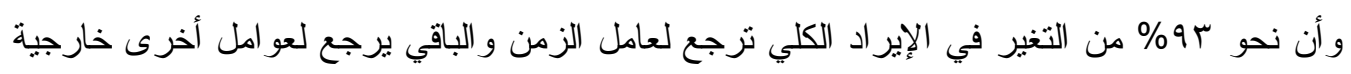
غير مقيسة بالمعادلة.

\section{- V تطور صافى العائد الفدانى:}

تبين من جدول ( () أن متوسط صافي عائد الفدان لمحصول القمح في مصر خــلاد فتـــرة

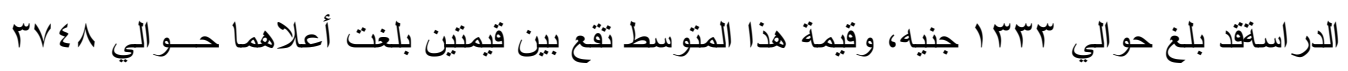

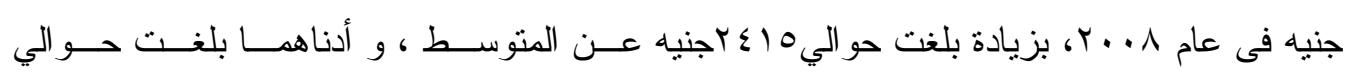

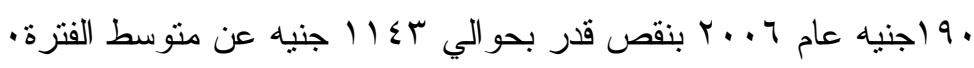

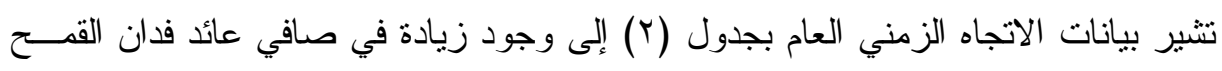

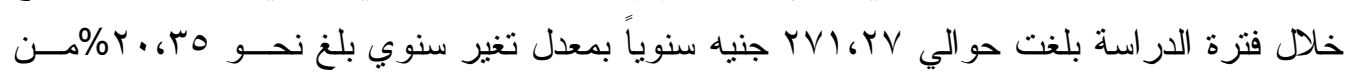

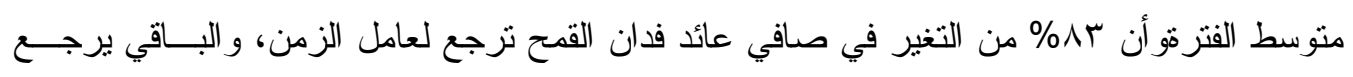
لعو امل أخرى خارجية. - مئ.

\section{1- تطور عائد الجنيه المستثمر في إنتاج القمح:}

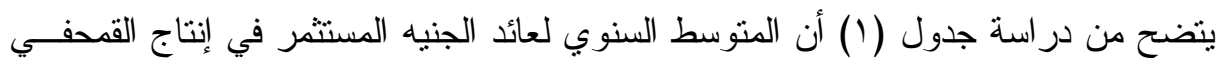

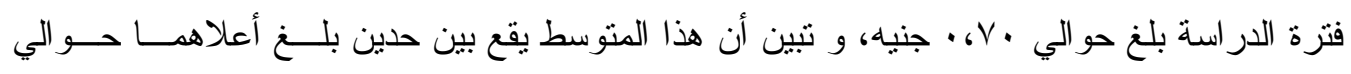

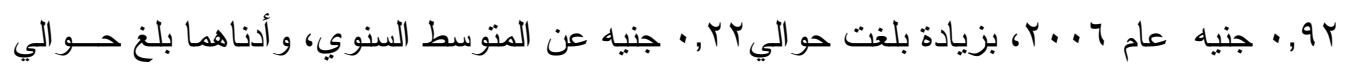

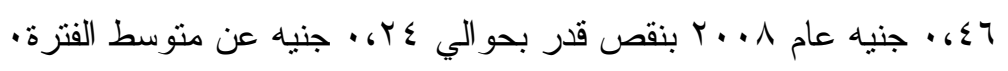

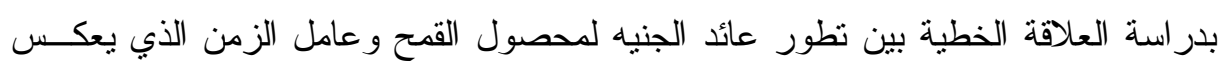

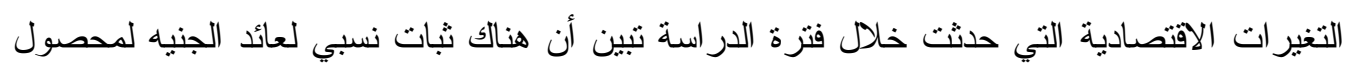
القمح طول فترة الدر اسة كما بجدول (r).

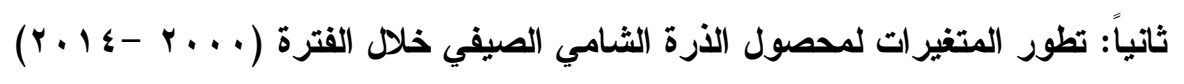
سوف يتم دراسة نظور أهم المتغيرات لمحصول الذرة الثنامي الصيفي خلالفترة الدر اسة على النحو 


\section{1- تطور المساحة المزروعة:}

تشير بيانات جدول (r) إلى أن المتوسطالسنوي للمساحة المزروعة بالذرة الثامية الصيفي

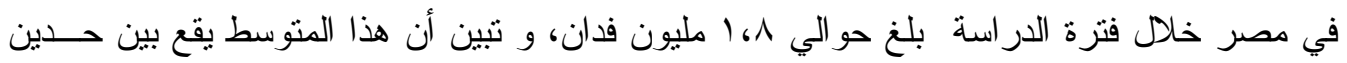

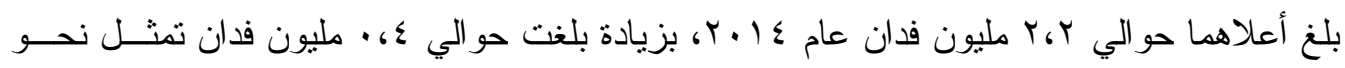

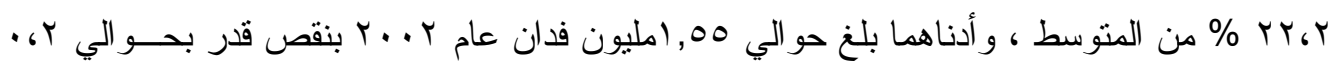

$$
\text { مليون فدان عن متوسط الفترة. }
$$

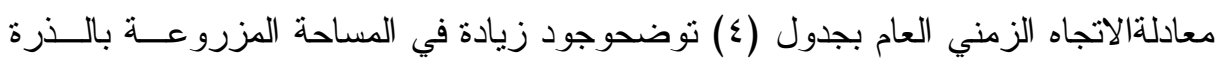

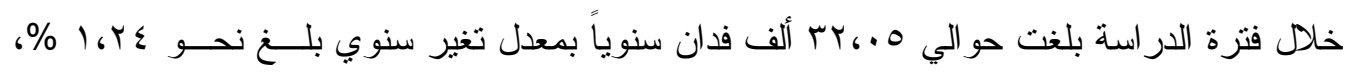

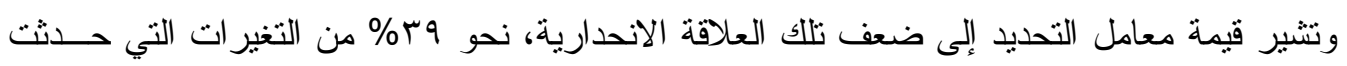

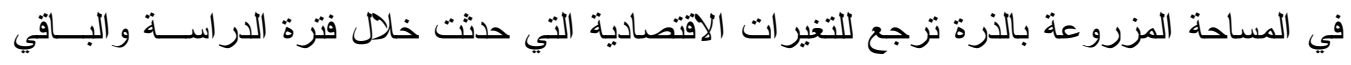
يرجع لعو امل أخرى خارجية.

r - تطور الإنتاجية الفدانية:

تثشير بيانات جدول (r) إلى أن المتوسطالسنوي للإنتاجية الفدانية لمحصول الذرة الثــامية

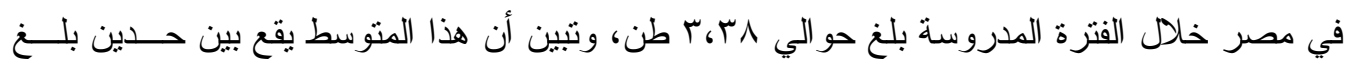

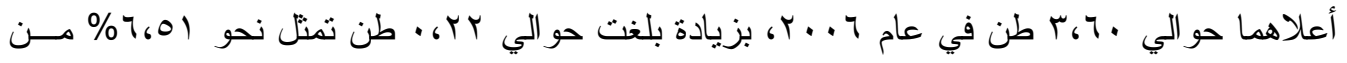

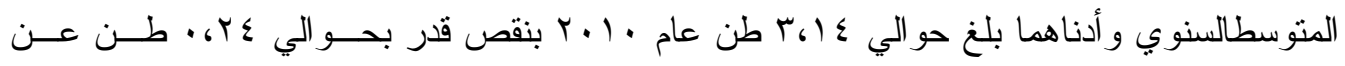
منتوسط الفترة.

بدر اسة العلاقة الخطية بين تطور الإنتاجية الفدانية للذرة الثامية وعامل الزمن الذي يعكس

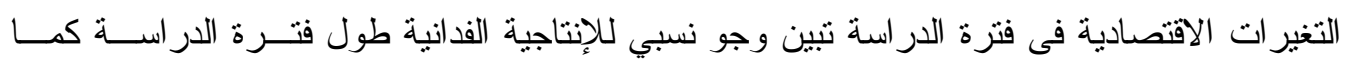

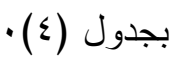

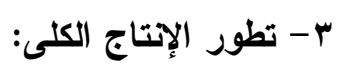
تبينبيانات جدول (ץ) أن المنوسط السنوي للإنتاج الكلي من الذرة الثامية في مصرفى فترة

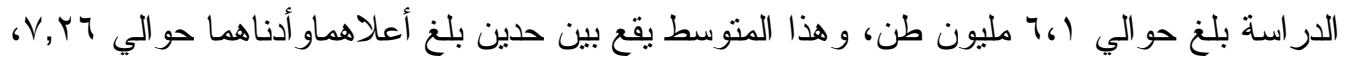

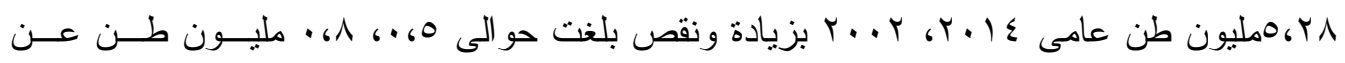

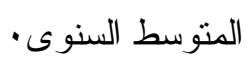

تشير معادلة الإتجاه الزمني العام بجدول (§) إلى زيادة في الإنتاج الكلي من الذرة بحوالي

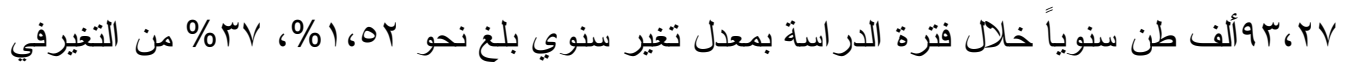

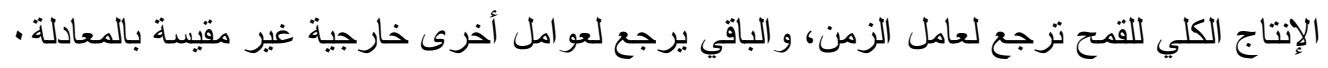
צ - تطور السعر المزرعى: اتضح من بيانات جدول (ب) أن المتوسط السنوي للسعر المزرعي للأرة في مصر خــله

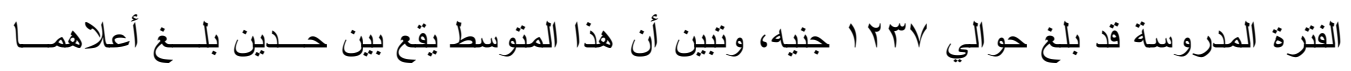

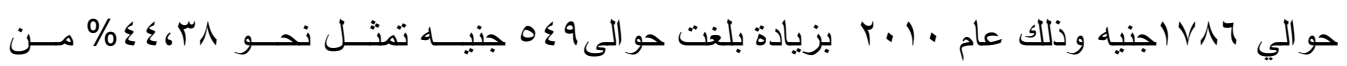




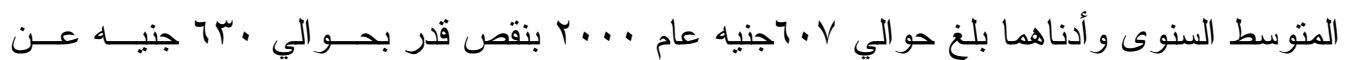
متوسط الفترة.

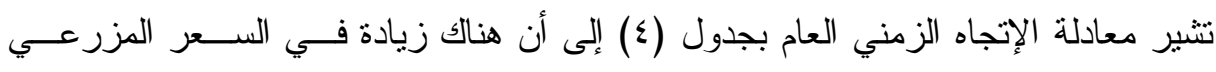

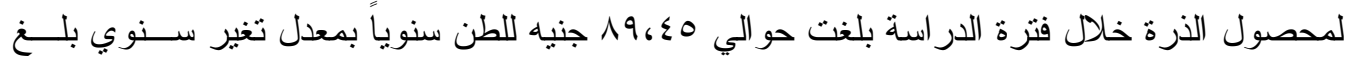

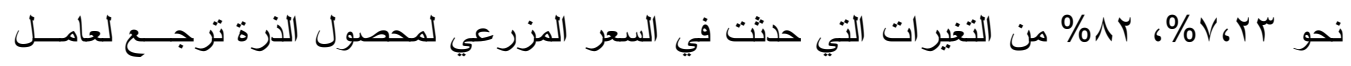
الزمن، و الباقي برجع لعو امل أخرى خارجية غير مقدرة بمعادلة الاتجاه الزمنى العام ل

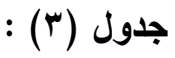

تظور أهم العوامل المؤثرة علي إنتاج محصول الذرة الشامية في مصر

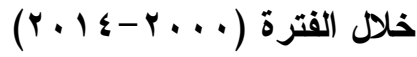

\begin{tabular}{|c|c|c|c|c|c|c|c|c|}
\hline بالجنيأه & صنيه للفدان العائد & الإير اد & التكاليف & السعر جنيه & بالألف & للإلطناجن & فالألف & السنوات \\
\hline . .VI & ovr & $r \ldots r$ & $1 \leqslant r$. & $7 . V$ & . & r.r. & $r \ldots r$ & r... \\
\hline $.6 V$. & IT & YI. & $1 \leq V Y$ & $71 \leq$ & $0 \wedge 49$ & $r, \leqslant r$ & 1811 & $r \ldots l$ \\
\hline .679 & 109 & qur & $1 \leqslant \Lambda$. & q ד & orvr & r،s. & 100r & $r \ldots r$ \\
\hline $.6 V Y$ & 719 & rTrA & 18.9 & 794 & דYM & דוr.r & 1010 & $r \ldots r$ \\
\hline . ، & 1707 & ro.r & $1 \wedge \leq 7$ & דr. & orl. & & $10 V 1$ & $r \ldots \varepsilon$ \\
\hline .607 & $171 \%$ & עצ & r. 00 & 1. 1. & וזי & r.os & $1 \vee 9 \leq$ & r... \\
\hline a & $r \leqslant \vee \wedge$ & $0 \curlyvee \Lambda \leq$ & Yr. T & 1.89 & A & r. & 1079 & $r . r$ \\
\hline $.6 \leq 7$ & $r q . \wedge$ & & YTYE & $10 \times 9$ & OOHY & r. $\leq \leqslant \leq$ & 17.1 & $r \ldots v$ \\
\hline . . & r 109 & & rrqv & $10 \wedge 7$ & ג & r. ، $\leqslant$ & $1 \wedge 7$. & $r \ldots \Lambda$ \\
\hline .61 & & $\leq 7 \leq V$ & r.r & Irvq & $\Delta \wedge \ldots$ & r.rv & $|V Y|$ & $r \ldots q$ \\
\hline צ7. & $1 \wedge 9 \wedge$ & 07.1 & rvi. & IV^צ & ITVE & r.l $1 \leq$ & 1991 & $r .1$. \\
\hline • • & $T \vee \wedge$ & $\varepsilon \vee 7$. & $\varepsilon \cdot \Lambda r$ & $1 \leq Y 1$ & ०^৭4 & هr.r & $1 v \otimes 9$ & $r .11$ \\
\hline . ، & $9 \vee \wedge$ & Orrv & $\leq \pi \leq$. & 1090 & VYII & r.rs & riov & $r \cdot I r$ \\
\hline • • & vor & $0 \leqslant \wedge \wedge$ & $\leq V Y_{0}$ & 170r & $v_{1} .1$ & rr.r & rirq & $r .1 r$ \\
\hline . $九 \wedge 9$ & 711 & A A & \& qrV & 1741 & VYOA & r.rr & Y1人 & $r \cdot 1 \leq$ \\
\hline .671 & $|r v|$ & $\varepsilon r \leq \tau$ & 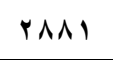 & IrrV & $71 Y \leq$ & r.rA & $|\wedge| \leq$ & المتوسط \\
\hline
\end{tabular}

المصدر: وزارة الزراعة واستصلاح الأراضي، قطاع الشؤون الاقتصادية، نشرة الاقتصاد الزراعي 


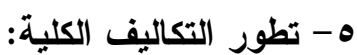

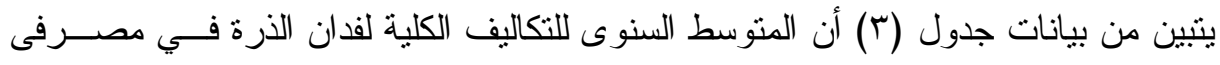

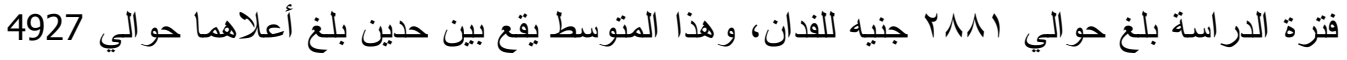

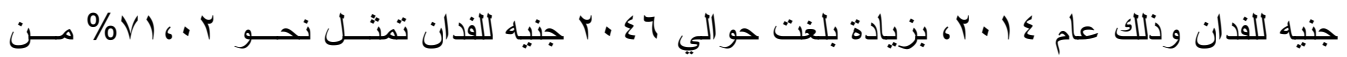

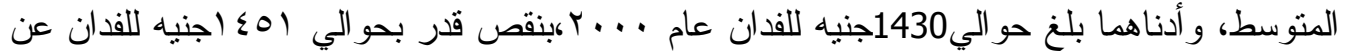
متوسط الفترة. - من

بدر اسة العلاقة الخطية بين تطور التكاليف الكلية وعامل الزمن تنييوجود زيادة في التكاليف

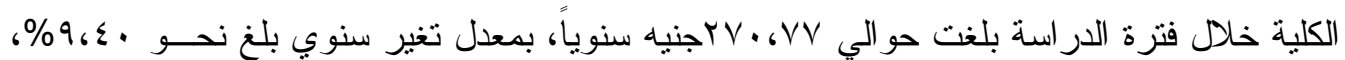

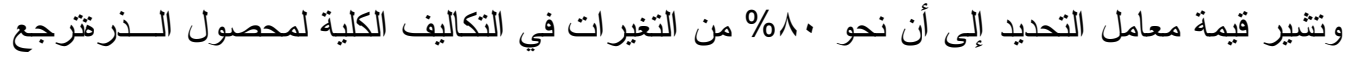
لعامل الزمن و الباقي يرجع لعو امل أخرى خارجية غير مقيسة فى معادلة الاتجاه الزمنى العام بجدول

$$
\text { ד - تطور الإيراد الكلي: }
$$

بدر اسة جدول (r) تبين أن المتوسطالسنوي للإير اد الكلي لفدان الذرة في مصر خلال فتــرة الدر اسة بلغ حو الي 4246 جنيه، وتبين أن قيمة هذا المتوسط يقع بين حدين بلغ أعلاهما حو الي 5684

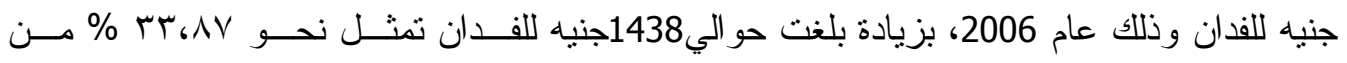

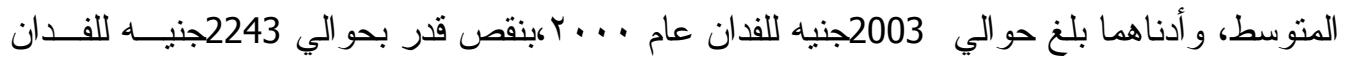

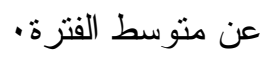
تشير معادلة|لاتجاه الزمني العام بجدول (ع) لوجود زيادة سنوية في الإير ادالفــدانى للــــرة

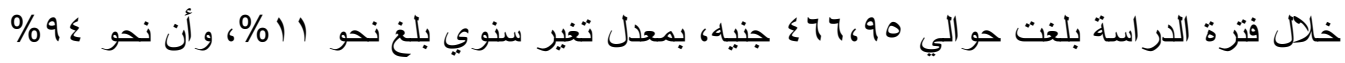

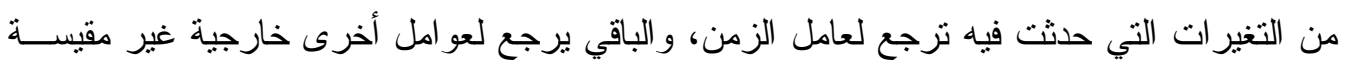
بالمعادلة.

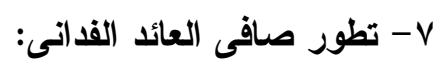
توضح بيانات جدول (r) أن متوسط صافي العائد الفدانى لمحصول الذرة في مصر خــلادل

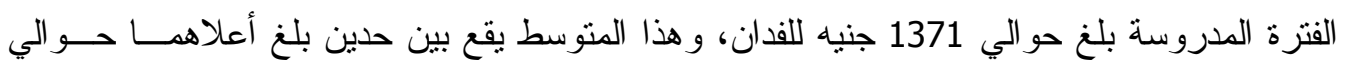

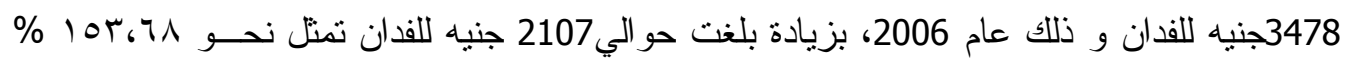

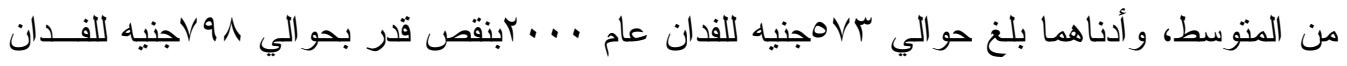

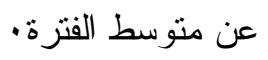
تثنير معادلة الاتجاه الزمني العام بجدول (ع) إلى أن هناك زيادة سنوية في صافي العائد

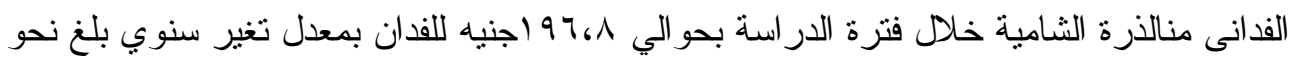

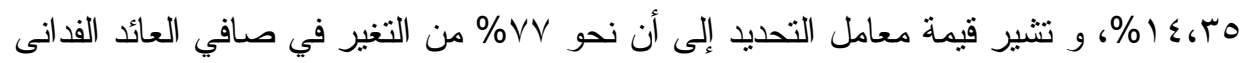
لمحصول الذرة نرجع لعامل الزمن و الباقي يرجع لعو امل أخرى خارجية غير مقامل مقدرة في في معادلة

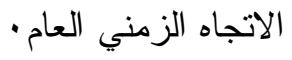




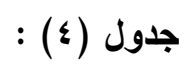

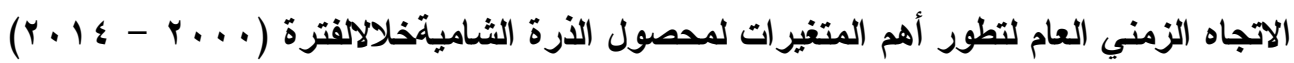

\begin{tabular}{|c|c|c|c|c|}
\hline معدل التغير \% & قيمة (ف) & נر & المعادلة & المتغير \\
\hline $1, r \varepsilon$ & A.rq & .649 & 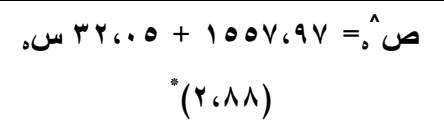 & المساحة المزروعة \\
\hline- & $1.8 V$ & .61 & 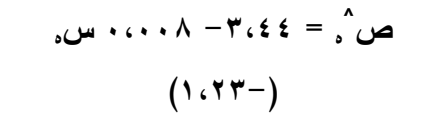 & الإنتاجية الفدانية \\
\hline $1.0 \%$ & V.7Y & . GrV & 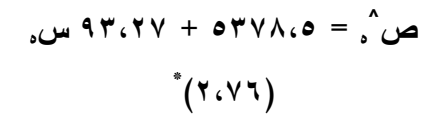 & طن للفدان الإنى \\
\hline VGrT & 0.600 & . ‘Ar & 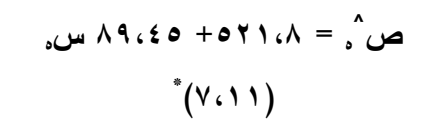 & جنيه للطن المزرعى \\
\hline q، \&. & Y99.7 & $\cdot ، \Lambda$. & 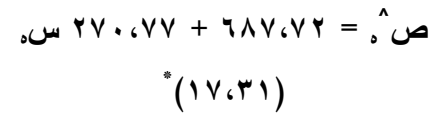 & جنيه للفدان الكلية \\
\hline $116 \ldots$ & $Y .0,7 \leq$ & .69 & 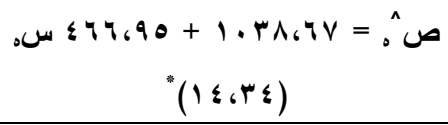 & جنيه للفدان الإير الكلى \\
\hline D & $\leq \varepsilon 6 \vee 7$ & $\cdot 6 \mathrm{VV}$ & 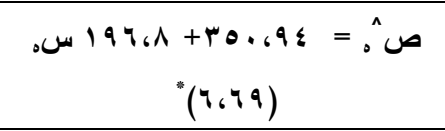 & صنيه للفد العائد \\
\hline- & $1, \leqslant r$ & .61 & 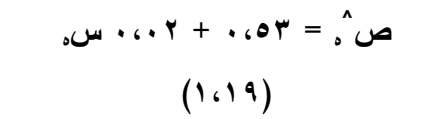 & عائد الجنيه \\
\hline
\end{tabular}

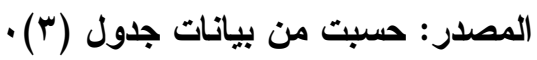

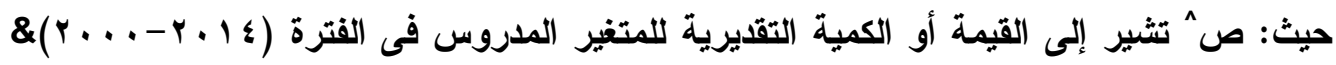

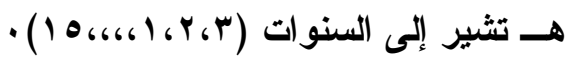
الأرقام ما بين الأقواس تثير إلى قيمة (ت) المحسوبة . \& \& تثبير إلى معنوية العلاقة عند مستوى . . 1

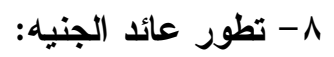
باستقر اء بيانات جدول (T) تبين أن منوسط عائد الجنيه المستثر في إنتاج محصول الــذرة

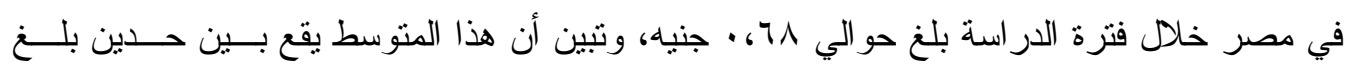

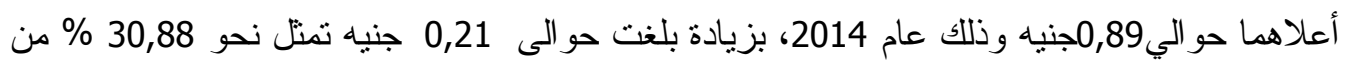

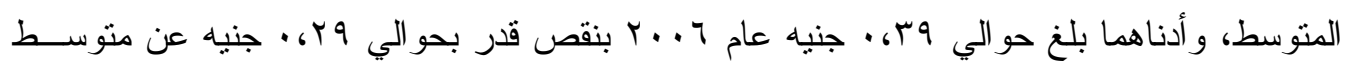
الفترة.

بدراسة العلاقة الخطية بين تطور عائد الجنيه المستثمر في إنتاج محصول الــذرة وعامـلـ

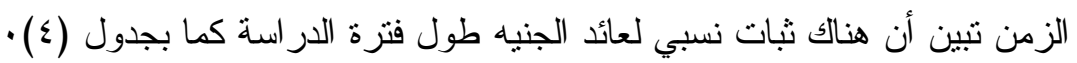




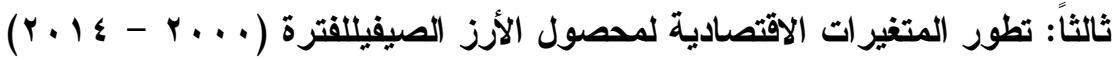

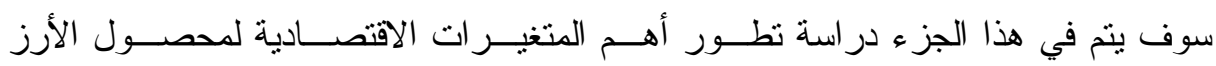

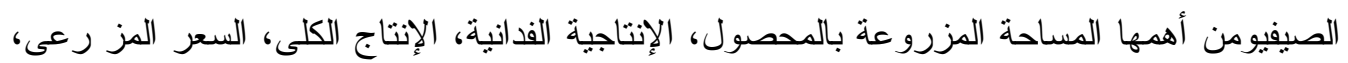

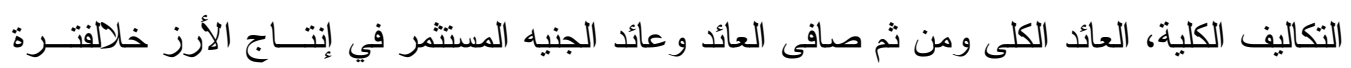
الدر اسة علىالنحو التالي: النهالئ

1 - تطور المساحة المزروعة: بدر اسة بيانات جدول (0) اتضح أن المتوسط السنوي للمساحة المزروعة بالأرز المصــري

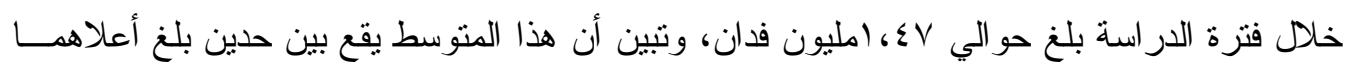

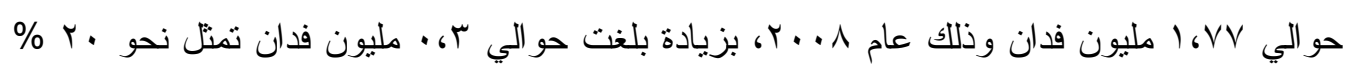

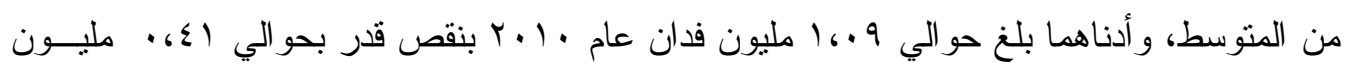

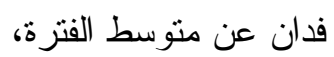

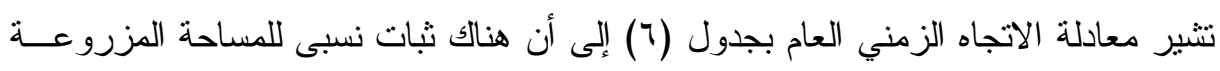
بالأرز طول فترة الدراسة أب أنها تدور حول متوسطها السنوي. جدول (0) : (0)

تطور أهم العو امل المؤثرة علي إنتاج محصولائرز الصيفي فى مصر خلا الفترة $(r+1 \varepsilon-r \ldots$

\begin{tabular}{|c|c|c|c|c|c|c|c|c|}
\hline بالجنيه & صافي & الإلير اد & التكاليف & السعر المز & بالألفت & للإلطدان & بالألففدانة & السنوات \\
\hline 1,41 & orl & TYYT & $179 r$ & OAY & $099 \mathrm{~V}$ & r.Ar & $10 \mathrm{~V}$. & $r \ldots$ \\
\hline $1, M V$ & $7 Y \leq$ & $r r . q$ & 1710 & OQr & OYYT & $r .9$. & $1 \mathrm{I} \varepsilon$. & $r \ldots l$ \\
\hline 1.01 & $\wedge 9$. & r 70. & 187. & 781 & 9111 & $r_{690}$ & $10 \leqslant V$ & $r \ldots r$ \\
\hline $16 \leqslant 9$ & 1.17 & r.vo & $r .0 q$ & 994 & $\leq \neg \vee \wedge$ & r. & 10.9 & $r \ldots r$ \\
\hline $16 \mathrm{VA}$ & 1104 & $\varepsilon r Y q$ & rrVT & $1 \cdot r \leq$ & $\neg r \leq \Lambda$ & \&.1T & lorv & $r \ldots \varepsilon$ \\
\hline $1, \lambda r$ & ט.r. & $\leq \leqslant 9$. & $r \leqslant 00$ & 1.79 & YITY & $\varepsilon_{\text {G }}$. & $1 \leq 7$. & $r \ldots o$ \\
\hline 1681 & $1 \wedge 9 \wedge$ & $\varepsilon 00\rceil$ & Y Y०A & $1 . V V$ & IVHA & E,rr & 1094 & $r \ldots r$ \\
\hline $1,1$. & $r \leq 7 r$ & OOYA & r. & $1 \leq 01$ & フトム & $\Gamma_{6}{ }^{\prime}$ & 1787 & $r \ldots v$ \\
\hline $1.0 Y$ & $r .09$ & $099 r$ & rarr & $1 \leq 70$ & VPrq & $\varepsilon 6.9$ & $1 V V$. & $r \ldots \Lambda$ \\
\hline 1.09 & rrrv & $7 . Y 0$ & 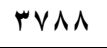 & $1 \leq 90$ & OOYI & $\varepsilon_{6} . r$ & Irv. & $r \ldots q$ \\
\hline 1.07 & rYqT & צr & $\varepsilon \cdot V \mu$ & $17 \ldots$ & $\varepsilon r Y \wedge$ & $r .97$ & 1.94 & $r+1$. \\
\hline l.Ar & $r q \leq q$ & $\Lambda \cdot V \gamma$ & $\leqslant \leqslant Y r$ & $r \ldots \Lambda$ & 0745 & $\varepsilon_{6} \cdot r$ & $1 \leq .9$ & $r .11$ \\
\hline $1.7 \mathrm{~V}$ & . & $\Lambda Y \vee \wedge$ & $\leq 9 \leq 1$ & $r .7 V$ & $0 \wedge 90$ & $\varepsilon \ldots 0$ & $1 \leqslant V Y$ & $r .1 r$ \\
\hline 1.74 & rrqA & $\Lambda 0 . r$ & 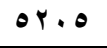 & Yll. & $0 \vee 19$ & $\varepsilon, . r$ & $1 \leq 19$ & $r .1 r$ \\
\hline 1.07 & $r .7 \leq$ & Norq & $0 \leq 70$ & rir. & $0 \leq 71$ & $\varepsilon \ldots \ldots$ & 1 114 & $r+1 \leq$ \\
\hline 1.71 & $r \cdot \Lambda l$ & 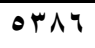 & o. & 1504 & O^H. & $\varepsilon$ & $1 \leq V 0$ & المتوسط \\
\hline
\end{tabular}

المصدر: وزارة الزراعة واستصلاح الأراضي، قطاع الثؤون الاقتصادية، نثرة الاقتصاد الزراعي أعداد 
r - تطور الإتتاجية الفدانية:

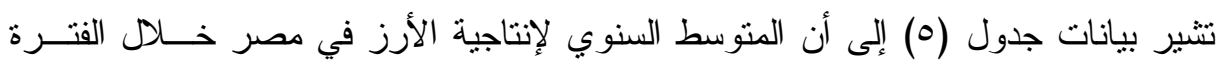

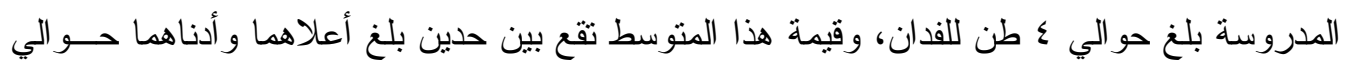

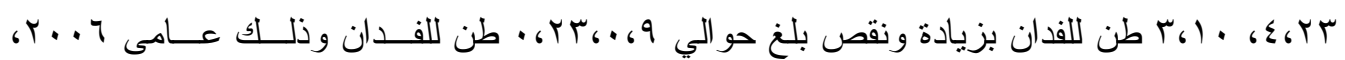

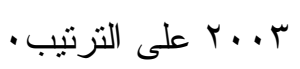

بدراسة العلاقة الخطية بين تطور الإنتاجية الفدانية للأرز وعامل الزمن ثبين أن هناك ثبات

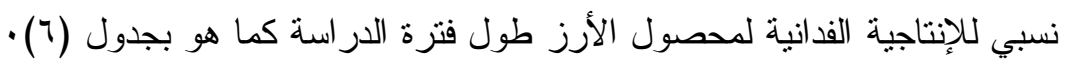

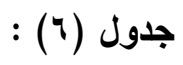

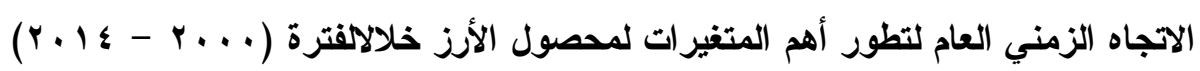

\begin{tabular}{|c|c|c|c|c|}
\hline معدل التغير \% & قيمة (ف) & r & المعادلة & المتغير \\
\hline- & r.A & .6 & $\begin{array}{c}\text { ص } 1 . \text {. } 199-10946 r=0 \\
(1,79-)\end{array}$ & بالأف فداحة المزروعة \\
\hline- & r.l. & .6 .9 & 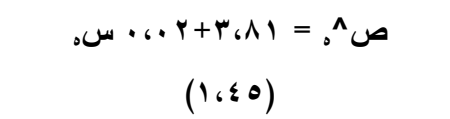 & الإنتاجية الفدانية \\
\hline- & $.61 \leq$ & $\cdot 6 \cdot 1$ & 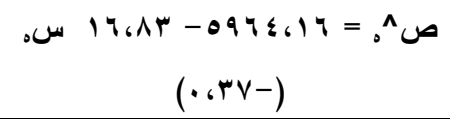 & طن للقدان الإنى \\
\hline$\Lambda_{6} 9 \leq$ & r৭४، & $.69 V$ & 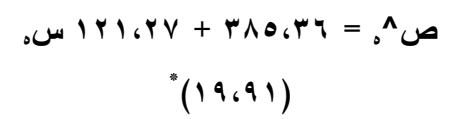 & جنيه للطن المزرعى \\
\hline$\Lambda_{6} \wedge_{7}$ & $\leqslant \triangle \wedge, \wedge r$ & $.69 V$ & 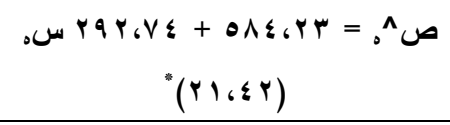 & جنيه اليف الكلية \\
\hline $1 \cdot 61$ & rr... & .697 & 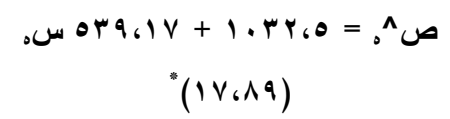 & جنيه للفدان الإيراد الكلى \\
\hline 11.79 & 110, & .69 & 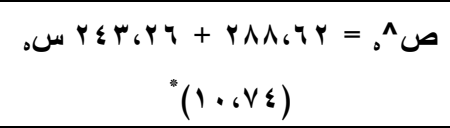 & صنيه للفدان العائد \\
\hline $1, Y \varepsilon$ & $\leq, Y \leq$ & . ro & 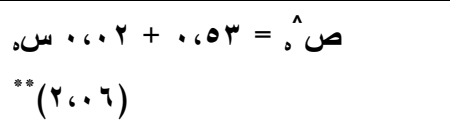 & عائد الجنيه \\
\hline
\end{tabular}

المصدر : حسبت من بيانات جدول (ه).

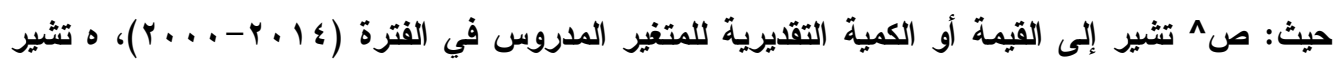

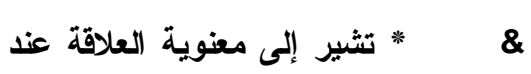

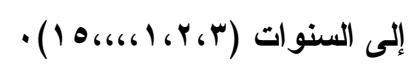

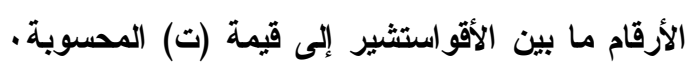

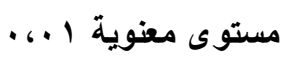

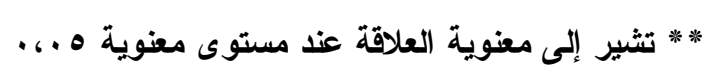




$$
\text { r- ت تطور الإتتاج الكلى: }
$$

اتضح من دراسة جدول (0) أن المنتسط السنوي للإنتاج الكلي للأرز في مصر خلال فترة

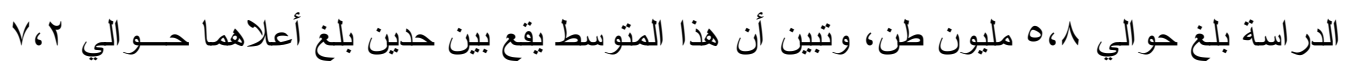

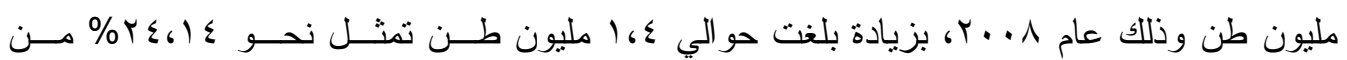

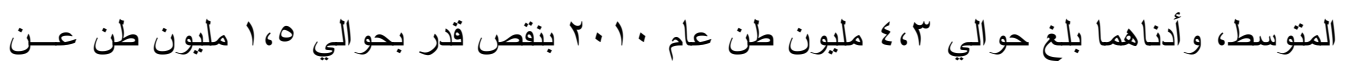

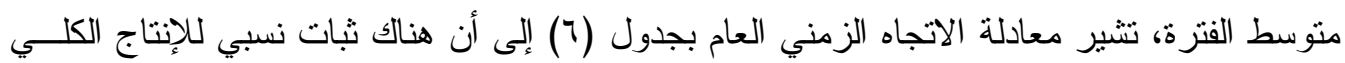
لكلأرز طول فتزة الدر اسة.

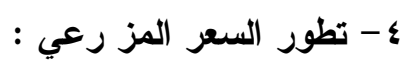

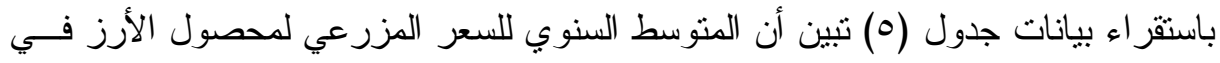
مصر خلال فترة الدراسة بلغ حوالي 1356جنيه، و تبين أن هذا المتوسط يقع بين حدين بلغ أعلاهما

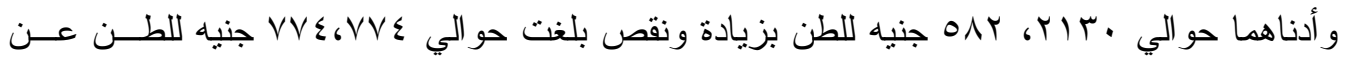

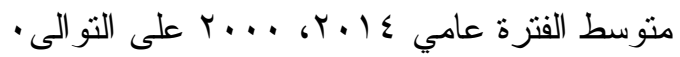

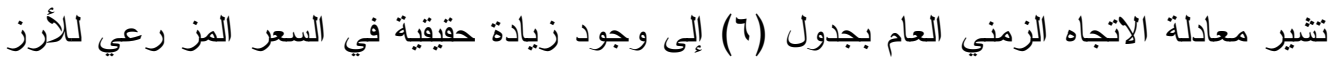

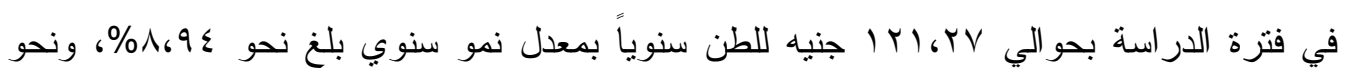

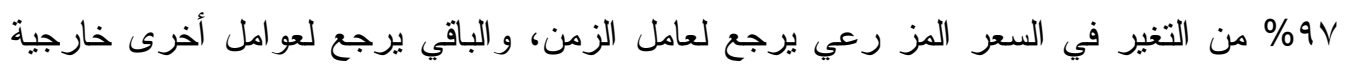

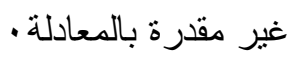

\section{ه- تطور التكاليف الكلية:}

تثشير بيانات جدول (0) إلى أن المتوسطالسنوي للتكاليف الكلية لفدانالأرز في مصر خــلد

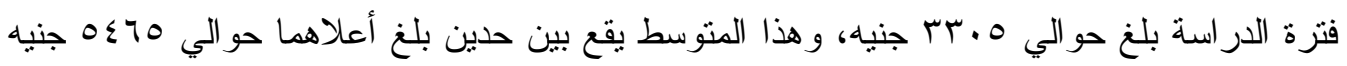

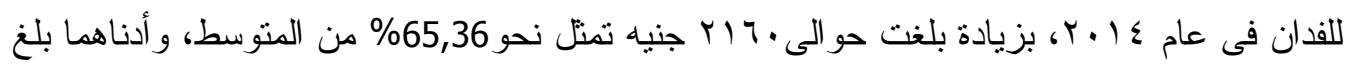

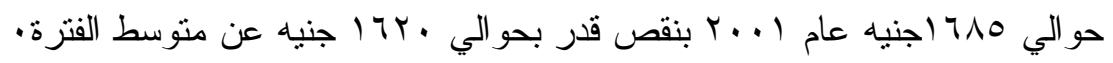

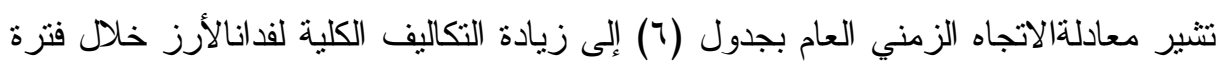

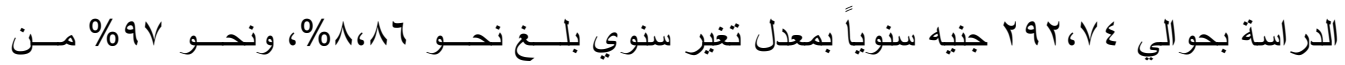

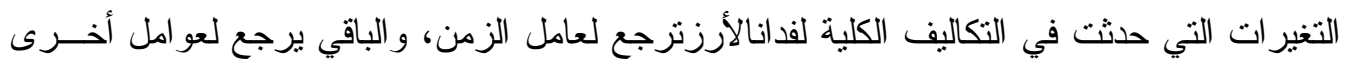
خارجية غير مقيسة.

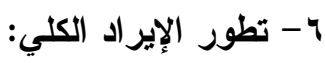
بيانات جدول (0) تشير إلى أن متوسط الإير اد الكلي لقدانالأرز في مصــر خــلدل فتـــرة

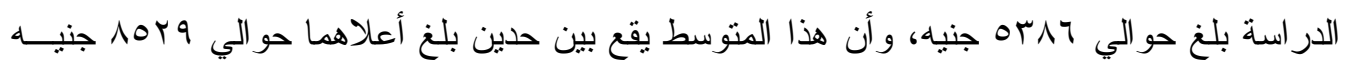

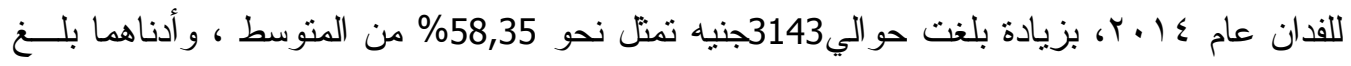

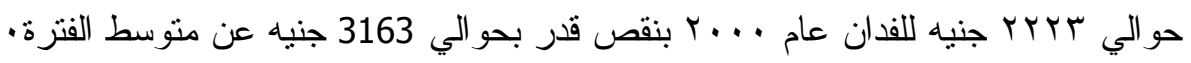

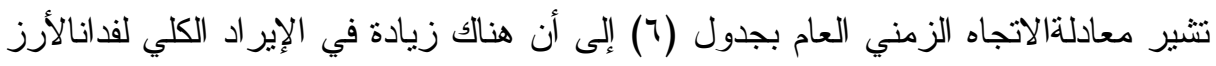

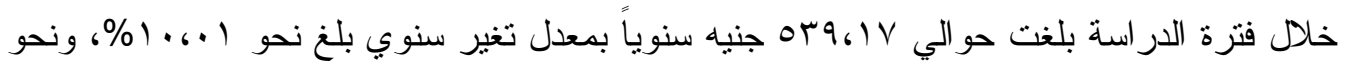


97\% من التغير في الإيراد الكلي لفدانالأرز نرجع لعامل الزمن، و الباقي يرجــع لعو امـلـ أخـــى خارجية غير مقيسة.

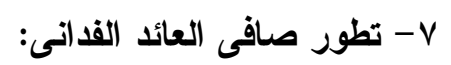

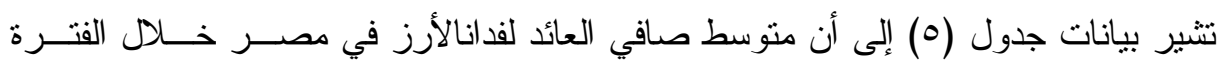

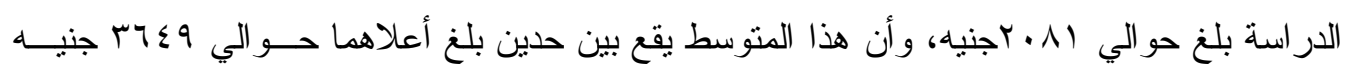

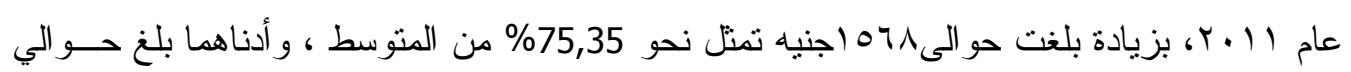

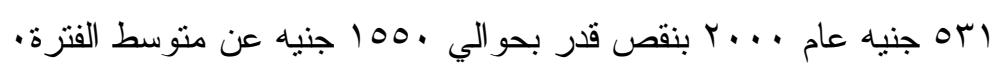

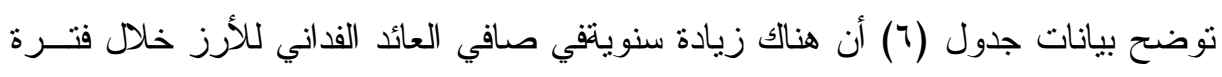

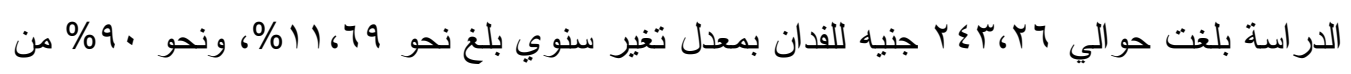

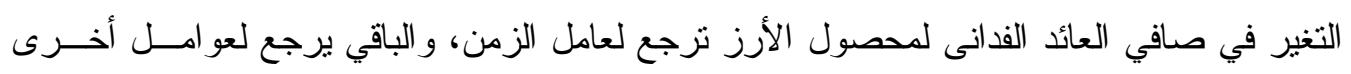
خارجية غير مقيسة .

1 - تطور عائد الجنيه:

تشير بيانات جدول (0) إلى أن منوسط عائد الجنيه المستثر في إنتاجالأرز في مصر خلال

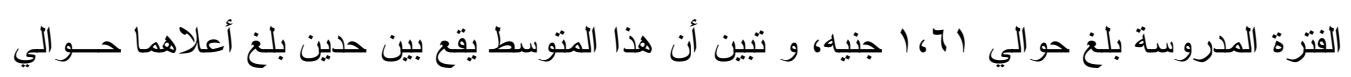

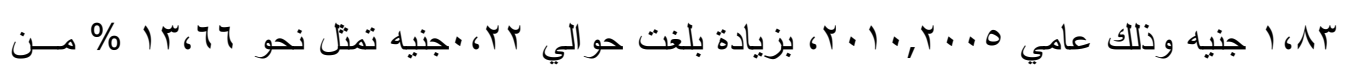

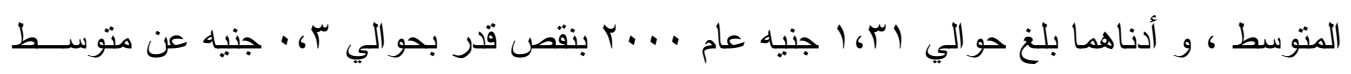
الفترة .

تبين بيانات الاتجاه الزمني العام بجدول (T) أن هناك زيادة سنوية في عائد الجنيه المستثر

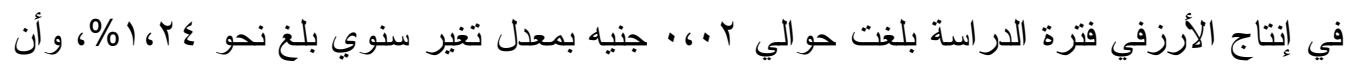

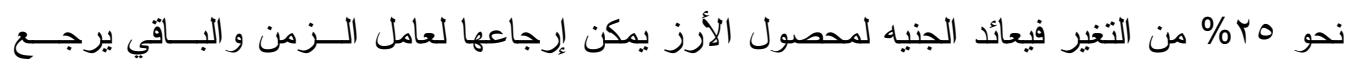
لعو امل أخرى خارجية غير مقيسة .وتثبير قيمة معامل التحديد إلى ضعف تلإنك العلاقة الإنحدارية.

\section{مصفوفة تحليل السياسات لأهم محاصيل الحبوب}

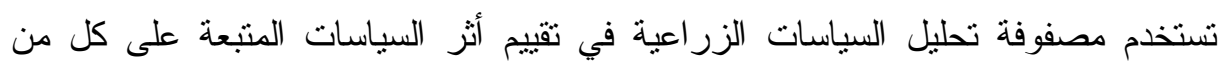

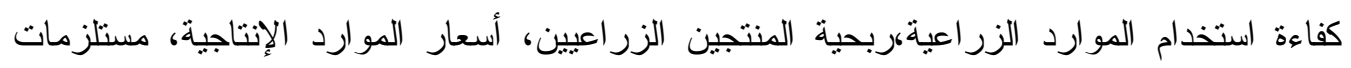

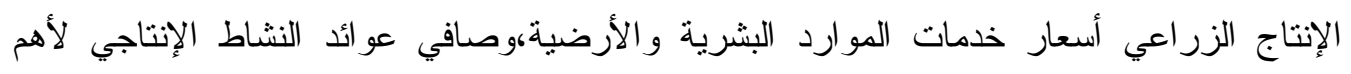
السلع الزر اعية الإستر اتيجية وذللك من خلال مقارنة عو ائد وتكاليف المحاصيل مقيمة مالياً أي وفقاً

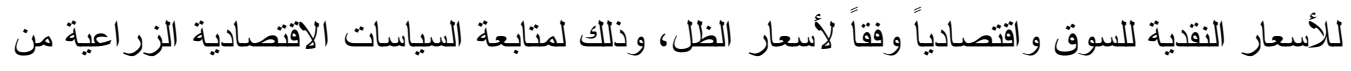

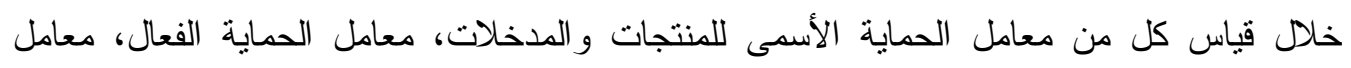

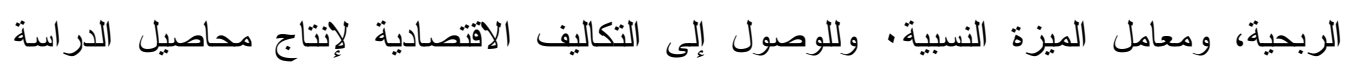

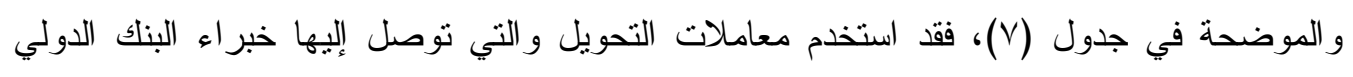

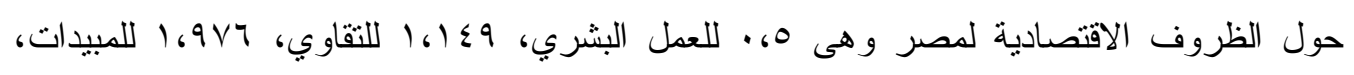

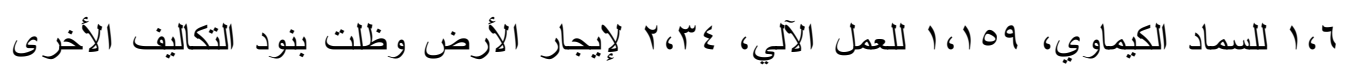




$$
\text { جدول (V) : ( ) }
$$

متوسط تكاليف الإتتاج لأهم محاصيل الحبوب مقيمة مالياً و اقتصادياً فى مصر للفترة

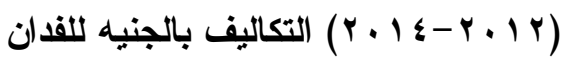

\begin{tabular}{|c|c|c|c|c|c|c|}
\hline \multicolumn{2}{|c|}{ الأرز الصيفي } & \multicolumn{2}{|c|}{ الأرة الشامية الصيفي } & \multicolumn{2}{|c|}{ القمح } & \\
\hline الاقتصادي التقيم & التقييم المالي & الاقتصادي & التقيم المالي & الاقتصادي & التيّيم & \\
\hline 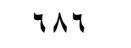 & ITVY & 790 & $1 r q$. & $\bullet \wedge \bullet$ & $11 \mathrm{~V}$ & العمل البشرى \\
\hline rq & rq & $1 \leqslant$ & $1 \varepsilon$ & 7 & 7 & العمل الحيواني \\
\hline $9 \leq \Lambda$ & $\wedge \backslash \wedge$ & Tr. & oro & VVI & 970 & العمل الأعلى \\
\hline$r \leq r$ & आI & $r \cdot r$ & Yчs & rqA & roq & التقاوي \\
\hline$\leqslant 1$ & $\leqslant 1$ & $r \cdot v$ & $r \cdot v$ & 11. & 11. & السماد البلدي \\
\hline 701 & $\varepsilon \cdot V$ & $\vee q$. & $\leq 9 \leq$ & viv & $\leqslant \leqslant \Lambda$ & السماد الكيماوي \\
\hline$r \leqslant q$ & IYY & ir. & 79 & 119 & 111 & المبيدات \\
\hline rVT & rVT & ५ч^ & rฯ & rVV & rVV & مصاريف أخرى \\
\hline 119 & rrvi & $r \cdot r V$ & rrrq & rqA & $r \cdot \leq q$ & التكاليف \\
\hline$\leqslant 017$ & 194. & $r r \leq r$ & $1 \leq r \wedge$ & $\leqslant 1 \wedge 7$ & $1 \vee \wedge 9$ & الإيجار \\
\hline Vדo & $0 Y \cdot Y$ & 9799 & ะ 7 V V & 8179 & 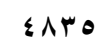 & التكاليف الكلية \\
\hline
\end{tabular}

المصدر: حسبت من بياتات الإدارة المركزية للاقتصاد الزراعي، قطاع الثئون الاقتصادية، نثرة الاقتصاد الزراعي أعداد مختلفة.

\section{مصفوفة تحليل السياسات لمحصول القمح}

$$
\text { 1 - معامل الحماية الاسمي للنواتج: }
$$

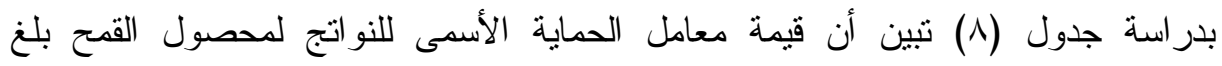

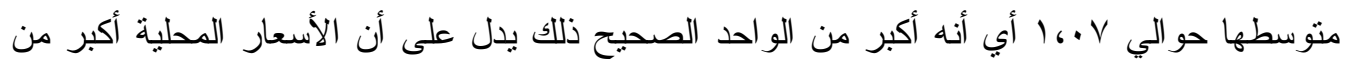

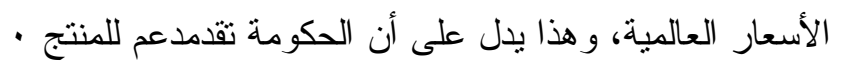
r - معامل الحماية الأسمى للمستلزمات:

يوضح جدول (^) أن معامل الحماية الأسمى للمستلزمات لمحصول القمح بلغت قيمته

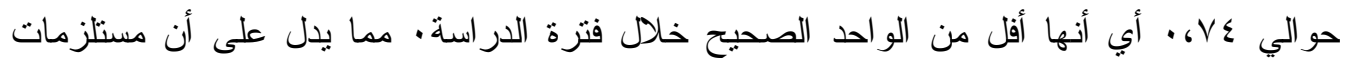

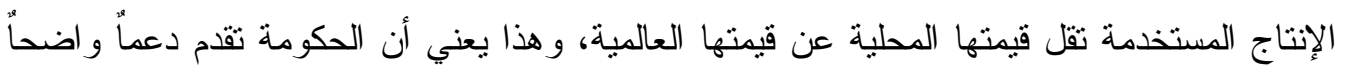

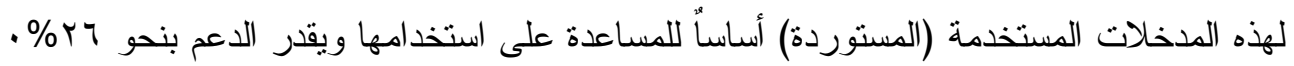




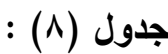

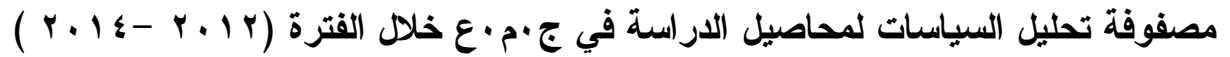

\begin{tabular}{|c|c|c|c|c|c|c|}
\hline العائد & الأرض & تكلفة الموارد & تكلفة مستلزمات & جملة الإير اد & التقييم & المحصول \\
\hline$\leqslant 1 \leqslant 0$ & $1 \vee \wedge 9$ & $1 \wedge \leqslant 1$ & ir.o & $\wedge 9 \wedge$. & التقييم المالي & \multirow{3}{*}{ القمح } \\
\hline 1 rio & $\{1 \wedge 4$ & & 1741 & $\Lambda r \wedge \varepsilon$ & الاقتصادي & \\
\hline rar. & (rrqv) & $\leq \vee q$ & $(\leqslant 17)$ & 094 & أثثر السياسة & \\
\hline $11 \% 0$ & $1 \leqslant Y \wedge$ & 1949 & $1 \times 99$ & 01.1 & التقيمم المالي & \multirow{3}{*}{ الثامية } \\
\hline rषq. & $r r \leqslant r$ & Irra & 1791 & $q . r q$ & الاقتصادي & \\
\hline$(10$ Y o ) & $(191 \leq)$ & 11. & $(r q 9)$ & (YYYA) & أثر السياسة & \\
\hline rol & 194. & rriq & 1.01 & AVYI & التقييم المالي & \multirow{3}{*}{ الصيفي } \\
\hline$I r v \cdot v$ & $\{014$ & 1874 & $1 \leqslant 04$ & $r \cdot r \leqslant r$ & الاقتصادي & \\
\hline$(१ १ १ ५)$ & $(Y \circ \wedge \uparrow)$ & 004 & $(r q \wedge)$ & $(11741)$ & أثز السياسة & \\
\hline
\end{tabular}

المصدر: حسبت من بياتات جدول (V)، الأرقام التي بين الأقو اس سالبة.

ب- - ب - معامل الحماية الفعال:

توضح بيانات جدول (^) أن منوسط معامل الحماية الفعال لمحصول القمح خلال فترة

الدراسة قدر بحوالى 101، أبي أنه أكبر من الواحد الصحيح مما يدل على أن هناك حماية فعالة

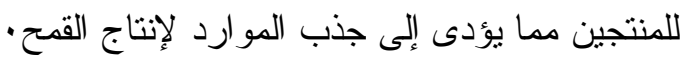
ع - معامل الميزة النسبية:

يتبين من بيانات جدول (^) أن منوسط معامل الميزة النسبية قدر بنحو Vآ، بوهو مايشير

$$
\begin{aligned}
& \text { إلى وجود ميزة نسبية لمصر في إنتاج القمح } \\
& \text { ه- معامل الربحية: }
\end{aligned}
$$

تبين من جدول (^) أن معامل الربحية قدر متوسطه بنحو ع، ب وهو مايدل على نجاح

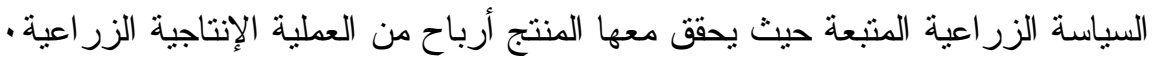

\section{مصفوفة تحليل السياسات لمحصول الأرة الثامية}

$$
1
$$

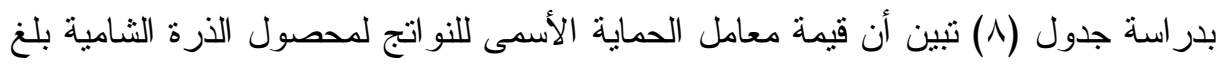

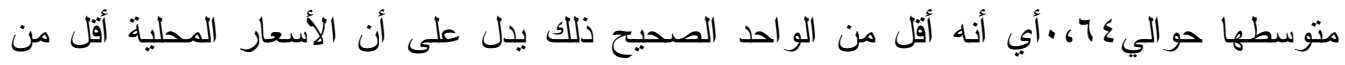

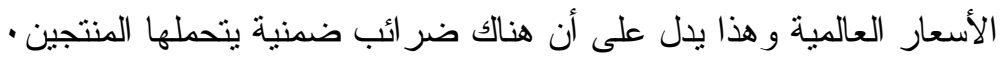




\section{r - ب - معامل الحماية الأسمى للمستلزمات:}

يوضح جدول (^) أن معامل الحماية الأسمى للمستلزمات لمحصول الذرة الثامية بلغت

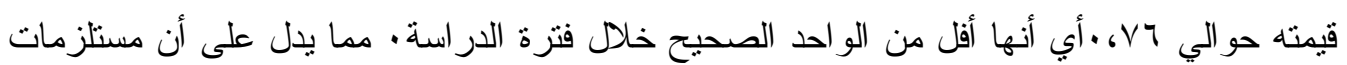
الإنتاج المتاجر فيها تقل قيمتها المحلية عن قيمتها العالمية، وهذا بعني أن الحكومة تقدم دعمُ و اضحاُ لهذه المدجلات المستخدمة (المستوردة) أساساُ للمساعدة على استخدامها ويقدر الدعم بنحو

$\%$. $\%$

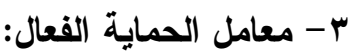

توضح بيانات جدول (^) أن متوسط معامل الحماية الفعال لمحصول الذرة الثامية خلال

فتزة الدراسة قدر بحوالى الا،.أي أنه أقل من الواحد الصحيح مما بدل على أن هنالك ضرائب ضمنية على المنتجين، مما يؤدى إلى هروب الموارد من إنتاج محصول الذرة الثامية.

ع - معامل الميزة النسبية:

يتبين من بيانات جدول (^) أن متوسط معامل الميزة النسبية لمحصول الذرة الثامية قدر بنحو 07، ، و هو مايشير إلى وجود ميزة نسبية لمصر في إنتاج محصول الذرة الثشامية.

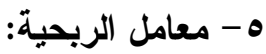

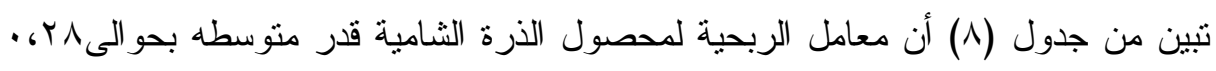
و هو مايدل على نجاح السياسة الزر اعية المنبعة حيث يحقق معها المنتج أرباح من العملية الإنتاجية

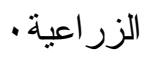

\section{مصفوفة تحليل السياسات لمحصول الأرز}

\section{1}

بدراسة جدول (^) تنين أن قيمة معامل الحماية الاسمي للنواتج لمحصول الأرز بلغ متوسطها حوالي باء، أبي أنه أقل من الواحد الصحيح ذلك يدل على أن الأسعار المحلية أقل من الأسعار العالمية، و هذا يدل على وجود ضر ائبضمنية بتحملها المنتجون للمحصول • r - ب - معامل الحماية الاسمي للمستلزمات:

يوضح جدول (^) أن معامل الحماية الاسمي للمستلزمات لمحصول الأرز بلغت قيمته حوالي سلV، أي أنها أقل من الواحد الصحيح خلال فترة الدراسة. مما يدل على أن أسعار مستلزمات الإنتاج المحلية أقل من نظيرتها العالمية، وهذا يعني أن الحكومة نقدم دعماً و اضحاً لهذه

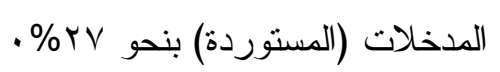




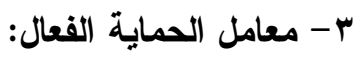

توضح بيانات جدول (^) أن متوسط معامل الحماية الفعال لمحصول الأرز خلال فترة

الدراسة قدر بحوالى اء،.أي أنه أقل من الواحد الصحيح مما يدل على أن هناك ضر ائب ضمنية

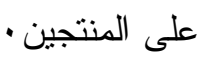

ع - معامل الميزة النسبية:

يتبين من بيانات جدول (^) أن متوسط معامل الميزة النسبية لمحصول الأرز قدر بحوالى

צr، · و هو مايشير إلى وجود ميزة نسبية لمصر في إنتاج محصول الأرز ·

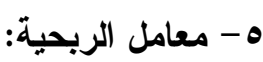

تبين من جدول (^) أن معامل الربحية لمحصول الأرز قدر متوسطه بنحو ع، وهو مايدل

على عدم نجاح السياسة الزراعية المتبعة حيث لايحقق معها المنتج أرباح من العملية الإنتاجية

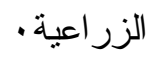




\section{المراجع}

1. إير اهيم محمد عبد العزيز الحفني"در اسة تحليلية لأثر السياسات السعرية على الفجوة الغذائية في

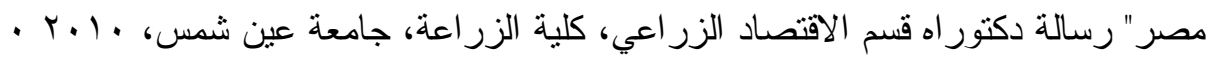

r. الجهاز المركزي للتعبئة العامة والإحصاء، المركز القومي للمعلومات، شبكةالإنترنت.

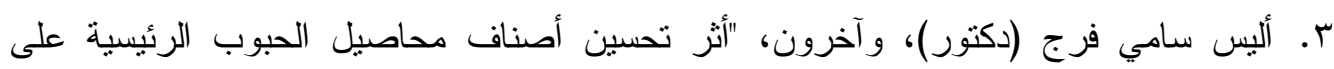
التتمية الزراعية في جمهورية مصر العربية"، الجمعية المصرية للاقتصاد الزراعي، المجلة

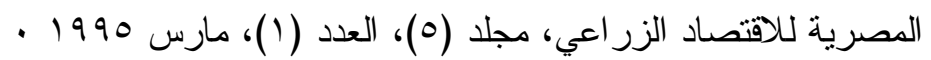

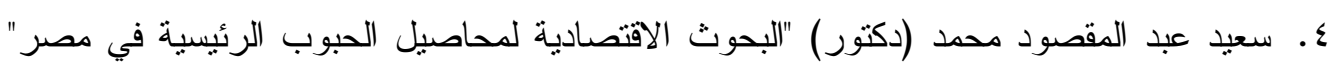

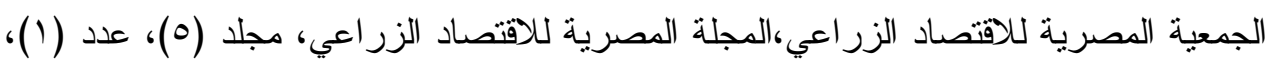
مارس 1990

ه. سمير عطية محمد عر ام (دكتور) و آخرون"التجارة الخارجية لأهم محاصيل الحبوب الغذائية قبل

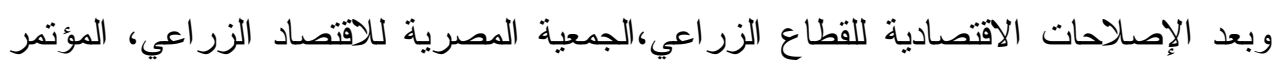

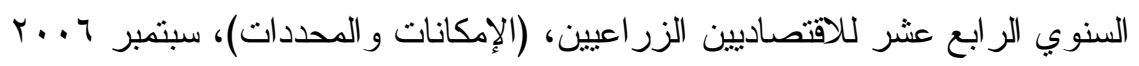

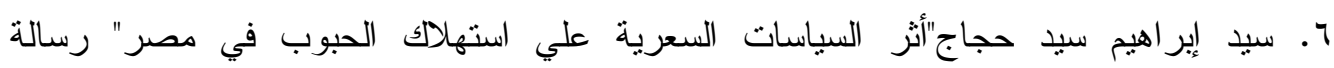

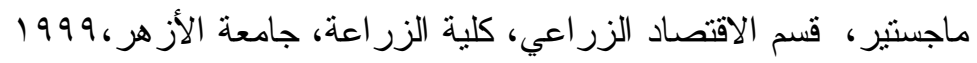

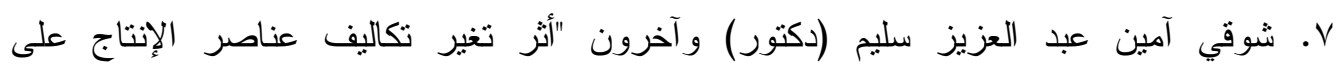
اقتصاديات أهم حاصلات الحبوب"، الجمعية المصرية للاقتصاد الزراعي، المؤتمر السادس لئرس

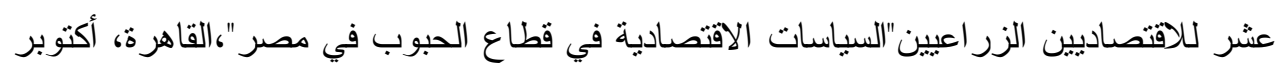
r... ^. محمد محمد الثاويش (دكتور) و آخرون "تحليل مقارن لإنتاجية أهم أصناف محصول القمح في

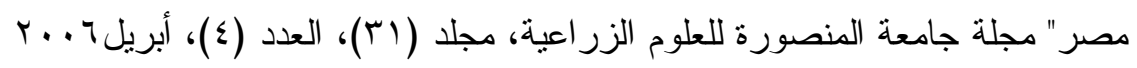
9. محمد محمد الثاويش (دكتور) "'تقدير الفاقد الكمي لمحصول القمح (در اسة حالة في محافظة

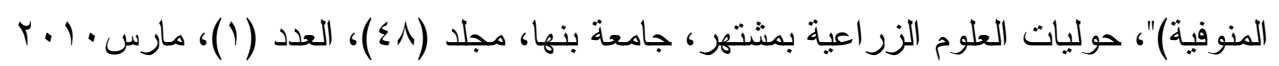

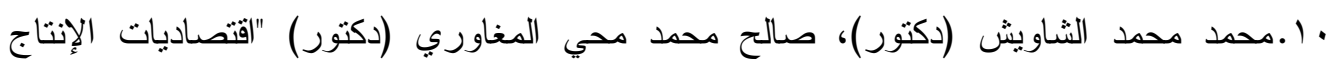

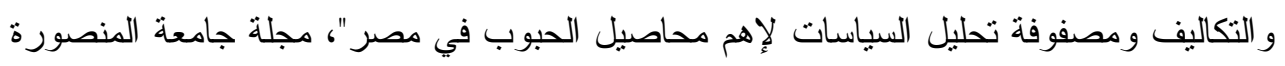

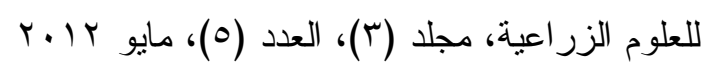

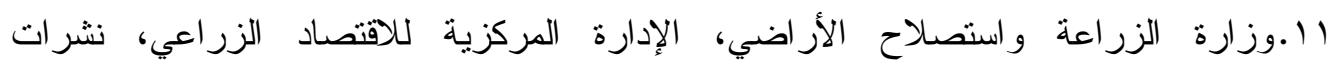
الاقتصادالزر اعي، أعداد مختلفة . 


\section{التوصيات}

ا- دراسة التوسع في زر اعة محصول القمح و الذرة الثامية في الأر اضي الجديدة وبما يتلاءم مع السياسة الزر اعية في مصر كمحاولة لنقليل الفجوة منهما. ץ- المحافظة على الرقعة المزروعة من محصول الأرز في ظل ندرة الموارد المائية المصرية حيث تحنل مصر المرنبة الأولى في الإنتاجية الفدانية، بالإضافة لكونه محصول تصديري هام

ז- ضرورة العمل على رفع إنتاجية كل من محصولى القمح والذرة الثامية وذلك من خلال اسنتباط سلالات حديثة عالية الإنتاجية الفدانية. ع- يجب تقديم دعم لمز ارعي الذرة الثامية والقمح لسد الفجوة حيث تشير النتائج إلى تحملهم

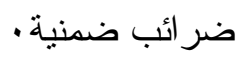
ه- ضرورة الاستمر ار في إنتاج الأرز لوجود ميزة نسبية لمصر في إنتاجه. 